\title{
Measurement of Low Amounts of Precipitable Water Vapor Using Ground-Based Millimeterwave Radiometry
}

PAUL E. RACETTE ${ }^{*}$, ED R. WESTWATER ${ }^{2}$, YONG HAN ${ }^{3}$, ALBIN J. GASIEWSKI ${ }^{4}$, MARIAN KLEIN $^{2}$, DOMENICO CIMINI ${ }^{5}$, DAVID C. JONES ${ }^{6}$, WILL MANNING ${ }^{7}$, EDWARD J. KIM ${ }^{1}$, JAMES R. WANG ${ }^{1}$, VLADIMIR LEUSKI ${ }^{2}$, PETER KIEDRON ${ }^{8}$

${ }^{1}$ NASA Goddard Space Flight Center, Greenbelt, Maryland

${ }^{2}$ Cooperative Institute for Research in Environmental Sciences, University of Colorado/NOAA/ Environmental Technology Laboratory, Boulder, Colorado.

${ }^{3}$ NOAA/National Environmental Satellite Data and Information Service, Silver Spring, Maryland

${ }^{4}$ NOAA/Environmental Technology Laboratory, Boulder, Colorado

${ }^{5}$ CETEMPS, University of L'Aquila, L'Aquila, Italy

${ }^{6}$ Met Office, FitzRoy Road, Exeter, United Kingdom

${ }^{7}$ Joint Center for Earth Systems Technology, University of Maryland Baltimore County, Baltimore, Maryland

${ }^{8}$ Atmospheric Sciences Research Center, SUNY at Albany, Albany New York

- Corresponding author address: Paul Racette, NASA/GSFC, Mail Code 555, Greenbelt, MD, 20771, Paul.E.Racette@nasa.gov 


\begin{abstract}
Extremely dry conditions characterized by amounts of precipitable water vapor (PWV) as low as 1-2 mm commonly occur in high-latitude regions during the winter months. While such dry atmospheres carry only a few percent of the latent heat energy compared to tropical atmospheres, the effects of low vapor amounts on the polar radiation budget - both directly through modulation of longwave radiation and indirectly through the formation of clouds - are considerable. Accurate measurements of precipitable water vapor (PWV) during such dry conditions are needed to improve polar radiation models for use in understanding and predicting change in the climatically sensitive polar regions. To this end, the strong water vapor absorption line at $183.310 \mathrm{GHz}$ provides a unique means of measuring low amounts of PWV. Weighting function analysis, forward model calculations based upon a 7-year radiosonde dataset, and retrieval simulations consistently predict that radiometric measurements made using several millimeter-wavelength (MMW) channels near the $183 \mathrm{GHz}$ line, together with established microwave (MW) measurements at the $22.235 \mathrm{GHz}$ water vapor line and $\sim 31 \mathrm{GHz}$ atmospheric absorption window can be used to determine within 5\% uncertainty the full range of PWV expected in the Arctic. This unique collective capability stands in spite of accuracy limitations stemming from uncertainties due to the sensitivity of the vertical distribution of temperature and water vapor at MMW channels.

In this study the potential of MMW radiometry using the $183 \mathrm{GHz}$ line for measuring low amounts of PWV is demonstrated both theoretically and experimentally. The study uses data obtained during March 1999 as part of an experiment conducted at the Department of Energy's Cloud and Radiation Testbed (CART) near Barrow, Alaska. Several radiometers from both NOAA and NASA were deployed during the experiment to provide the first combined MMW and MW ground-based data set during dry arctic conditions. Single-channel retrievals of PWV were performed using the MW and MMW data. Discrepancies in the retrieved values were found to be consistent with differences observed between measured brightness temperatures (TBs) and forward-modeled TBs based on concurrent radiosonde profiles. These discrepancies are greater than can be explained by measurement error alone and are attributed to absorption model uncertainty. We discuss here the measurements, retrieval technique, and line model discrepancies along with difficulties and potential of MMW/MW PWV measurement.
\end{abstract}




\section{Introduction}

The polar regions are an important but ill-understood component of the global climate system. In response to the need for improved understanding of the effect of the polar regions on global climate, the Department of Energy's (DOE) Atmospheric Radiation Measurement (ARM) program established a climate observation site on the North Slope of Alaska/Adjacent Arctic Ocean (NSA/AAO) in 1997 (Stamnes et al. 1999; Stokes and Schwartz 1994; Ackerman and Stokes 2003). The establishment of this site followed the yearlong Surface Heat and Energy Budget of the Arctic (SHEBA) study (Curry et al. 2000); many similar instruments deployed during SHEBA are deployed at the NSA/AAO Cloud and Radiation Testbed (CART) site. Many of the important scientific questions associated with the Arctic region are discussed by Stamnes et al. (1999) and by Curry et al. (1996). These studies have shown that water vapor and clouds play an essential role in moderating the Earth's climate and that accurate measurements of the atmospheric water distribution are needed to adequately model the Earth's radiation budget. In our work, we focus on the difficult problem of measuring precipitable water vapor during cold and dry conditions.

Detailed spectral measurements of downwelling infrared radiation were available during SHEBA and are currently being recorded at the NSA/AAO CART site. The measurements were made by an extended-range version of the Atmospheric Emitted Radiance Interferometer (AERI-ER) (Revercomb et al. 1998; Tobin et al. 1999), which covers the spectral range from 380 to $3000 \mathrm{~cm}^{-1}$. As has been shown by Clough et al. (1992), the transparent portion of the water-vapor rotational band from 250 to $600 \mathrm{~cm}^{-1}$ is important for the Earth's energy balance. Modeling of this region is thus of particular importance. The modeling of measurements taken by AERI-ER during SHEBA was done using detailed Line-by-Line Radiative Transfer Models (LBLRTM) (Tobin et al. 1999). Their results showed discrepancies between measurements and calculations that could be ascribed to errors in the radiosonde measurements of water-vapor profiles. Such concerns have plagued the ARM community and have been discussed by Lesht (1999), Clough et al. (1996, 1999), Turner et al. (2003), Wang et al. (2002), and Westwater et al. (2003). An important instrument used in identifying such problems has been the ARM dual-frequency microwave radiometer (MWR) (Liljegren 2000). However, the 
sensitivity of this instrument in measuring precipitable water vapor (PWV) at the low concentrations that frequently exist in the Arctic ( $P W V<0.5 \mathrm{~cm}$ ) has been questioned. Accordingly, the objective of our study is to examine the theoretical and experimental use of millimeterwave (MMW) and microwave (MW) radiometers to measure low amounts of PWV.

The measurement of PWV is well established using ground-based MW radiometry (Westwater 1978; Hogg et al. 1983; Janssen 1985). Dual-channel MWRs are operated routinely at the ARM CART sites at the Southern Great Plains (SGP) in Oklahoma, in the Tropical Western Pacific, and at the NSA/AAO (Stokes and Schwartz 1994; Ackerman and Stokes 2003). The MWRs operating at the Southern Great Plains and Tropical Western Pacific CART sites have been useful in identifying biases in radiosondes (Clough et al. 1996, 1999; Turner et al. 2003; Westwater et al. 2003). These radiometers are manufactured by Radiometrics Corporation, USA, (www.radiometrics.com) and have proven to provide reliable measurements of PWV under conditions of moderate to heavy water vapor burden along with integrated cloud liquid or liquid water path (LWP). A complete description of these instruments, as well as a description of their calibration procedure, is given by Liljegren (2000).

MMW radiometry has been used for more than two decades to measure tropospheric water-vapor distributions from aircraft and satellite platforms. It is particularly well suited for water vapor measurements because of the strong response to water vapor exhibited at the $183 \mathrm{GHz}$ and higher frequency absorption lines. Spectroscopic measurements made near the $183 \mathrm{GHz}$ line and adjacent "window" regions permit retrievals of profiles of water vapor (Wang et al. 1983; Kakar and Lambrigtsen 1984; Wang and Chang 1990). In 1991 water-vapor profiles based upon measurements made near the $183 \mathrm{GHz}$ line were first made by the Special Sensor Microwave/Temperature-2 (SSM/T-2) instrument onboard the Defense Meteorological Satellite Project (DMSP) F-11 satellite (Falcone et al. 1992). During the 1990s many studies were conducted on the use of MMW radiometry to measure water vapor, precipitation, and clouds. Wang et al. (1997) reported a technique for deriving three dimensional water-vapor profiles using MMW measurements made at oblique incidences. The effects of clouds on water-vapor profiles retrieved using MMW radiometry have also 
been investigated (Wang et al. 1992, 1997, 2001a). Wang et al. (1998) showed that ice clouds have minimal impact on measurements made between 90 and $220 \mathrm{GHz}$. This same frequency range was shown to be sensitive to the presence of liquid clouds. The application of airborne and spaceborne MMW measurements to retrieve PWV over the Arctic has been subject of more recent studies (Wang et al. 2001b, 2002). Though the application of nadir-viewing airborne and spaceborne MMW radiometry is well established, the application of ground-based MMW measurements has been less well investigated. Jackson and Gasiewski (1995) reported on comparisons of PWV measurements using ground-based MMW radiometry, radiosondes, and Raman lidar. More recently, Siegenthaler et al. (2001) report on measurements of ground-based retrievals of water-vapor profiles using a $183 \mathrm{GHz}$ spectrometer from the Jungfraujoch at an elevation of $3580 \mathrm{~m}$ in Switzerland. Their work demonstrated the application of MMW radiometry to high-altitude ground-based retrievals of water-vapor profiles.

Although the characteristics of the atmosphere in polar regions are not completely understood, it is widely recognized that during the winter months extremely dry conditions prevail. Serreze et al. (1995a) reported on the distribution and flux of water vapor over the Arctic based upon radiosonde observations launched at $70^{\circ} \mathrm{N}$ and higher over the period 1974-1991. Over the winter months between November and March the average PWV is below $2.5 \mathrm{~mm}$. Over the Arctic Ocean the average PWV during the winter months is $1.8 \mathrm{~mm}$ (Serreze et al. 1995b). These results are consistent with a study we performed using a seven year (1990-1996) set of radiosondes from the National Weather Service (NWS) station in Barrow, Alaska. Fig. 1 shows the probability distribution and the cumulative distribution functions of PWV measured at Barrow. The cummulative distribution shows that for $50 \%$ of the time the PWV is less than $\sim 5 \mathrm{~mm}$, thus, dry conditions exist during a substantial fraction of the year.

Obtaining accurate measurements of low amounts of vapor in the atmosphere is especially important for modeling longwave radiative fluxes during the polar winter months. Substantial variations in longwave emission caused by fluctuations in low amounts of water vapor directly affect the Arctic climate through both greenhouse trapping of radiation and cloud formation processes. These two mechanisms are 
suspected to have profound effects on the Arctic heat budget, and in turn, on the extent and seasonal duration of sea ice coverage and on polar weather.

In this study we present a theoretical basis for PWV measurement in an arctic environment using both MW and MMW radiometric data. We investigate the retrieval uncertainties associated with using a variety of measurement systems. We describe an experiment at the NSA/AAO facility in March 1999 designed to demonstrate the ability to measure low amounts of PWV, and then discuss the subsequent data analysis. We conclude with a summary and suggestions for further work.

\section{Theoretical basis for improved retrieval of low amounts of precipitable water vapor using MMW radiometry}

One motivation for our work was to examine the hypothesis that brightness temperature measurements at the operational frequencies used by the ARM MWR lack the sensitivity necessary to estimate PWV at low vapor concentrations and cold temperatures. A second hypothesis was that radiometers operating at millimeter wavelengths could supply valuable information under just these conditions. Finally, we hypothesize that a combination of MW and MMW channels could supply accurate measurements of PWV over the entire range of values encountered at the NSA AAO. In this study we focus primarily on clear conditions as verified using lidar and cloud radar operated at the NSA site.

\section{a. Sensitivity to water vapor and temperature}

One measure of sensitivity to profiles of water-vapor density $\rho_{v}$ and temperature $T$ is provided by the associated vertical weighting functions $W \rho_{v}, W_{T}$. The equations for the calculation of these functions, in the upward-looking case, are given by Westwater (1993). From our 7-year ensemble of radiosonde profiles from Barrow, Alaska, we calculated $T$ and $\rho_{v}$ weighting functions for each of these profiles. In Fig. 2, we present their averages over the conditions $0.0<\mathrm{PWV} \leq 5(\mathrm{~mm}), 5<\mathrm{PWV} \leq 10(\mathrm{~mm})$ and 10 $(\mathrm{mm})<$ PWV for several useful channels. Key features resulting from the nearly-linear response to water vapor at $23.8 \mathrm{GHz}$ and the decidedly nonlinear responses at the 183 $\mathrm{GHz}$ channels deserve comment. First, over the entire range of PWV the $23.8 \mathrm{GHz} W \rho_{\mathrm{v}}$ 
functions are almost independent of altitude; i.e., the TB is directly related to PWV. In addition, the sensitivity to $T$ at this channel is small, i.e., $W_{T} \cong 0$. Second, at the low values of PWV $(<5 \mathrm{~mm})$ the channels near $183 \mathrm{GHz}$ exhibit a $\sim 30$-fold increase in sensitivity to $\rho_{v}$, but have only a small sensitivity to T. At increasing amounts of PWV, the $183 \mathrm{GHz} W \rho_{\mathrm{v}}$ lose their sensitivity to $\rho_{\mathrm{v}}$ and become increasingly sensitive to $\mathrm{T}$. However, the combined behavior of the 23.8 and the $183 \mathrm{GHz}$ weighting functions suggests that an accurate PWV retrieval using all of the aforementioned channels can be realized for the entire range of clear-air conditions at the NSA/AAO location.

Another method of illustrating the joint linearity and sensitivity characteristics of the 23.8 and $183 \mathrm{GHz}$ channels is to plot calculated TB versus PWV (Fig. 3). As expected, the channel closest to the $183 \mathrm{GHz}$ water vapor line center (i.e. $183.31 \pm 1$ $\mathrm{GHz}$ ) is linear only for low PWV concentrations (PWV $<1 \mathrm{~mm}$ ), while the channels farther from the line are linear over a more extended range of PWV. The linear behavior of $23.8 \mathrm{GHz}$ over a wide range of PWV is also evident, although with relatively low sensitivity $(\sim 1.4 \mathrm{~K} / \mathrm{mm})$.

\section{b. Retrieval simulation studies}

PWV and LWP can be derived from dual-frequency MW radiometer measurements using a simple and robust linear non-iterative statistical retrieval algorithm. An a priori set of atmospheric profiles is used to derive regression coefficients relating the atmospheric opacity at the measurement frequencies (23.8 and $31.4 \mathrm{GHz})$ to LWP and PWV. The atmospheric opacity at a particular frequency is obtained from the brightness temperature (TB), an estimate of TB measurement errors, and an estimate of the mean radiating temperature at that frequency. Westwater (1993) provides a detailed description of the technique. The non-iterative statistical retrieval algorithm has the advantage that it does not require a temperature and humidity profile, i.e., a background field, and requires only very simple calculations. However, the technique requires seasonal and locationdependent regression coefficients.

In this section we describe an iterative statistical-physical algorithm for retrieving PWV and LWP from any combination of zenith-MW and/or MMW TB measurements (Jones and Racette 1998). There are a number of advantages to an iterative retrieval over 
a purely non-iterative statistical approach. First, at wavelengths with strong absorption, (e.g., near the $183 \mathrm{GHz}$ absorption line) the change in atmospheric brightness temperature is a highly nonlinear function of PWV. Near such features the iterative statistical-physical retrieval algorithm weights each data value according to its tangential response to the parameters being retrieved. Second, a background field can be used in the algorithm to more accurately describe the specific temperature and baseline humidity profiles. The iterative retrieval also accounts for the uncertainty of the data and errors in the forward radiative transfer model. And while the iterative retrieval has the disadvantage of being computationally intense, the relatively long sampling intervals for ground based observations and fast speeds of modern computers do not restrict its use.

The iterative statistical-physical algorithm that we have developed has several useful features. The observation frequencies can be readily selected without the need to re-compute regression coefficients. The absorption model that is used can also be readily interchanged for intercomparison purposes. The algorithm also generates estimates of the uncertainties in the retrieved parameters. In order to make the retrieval applicable to both ground-based and airborne up-looking observations, the retrieval algorithm was designed to operate at any observation pressure altitude and for any combination of channels. The retrieval algorithm is also easily modified to retrieve a single parameter (e.g. PWV) based upon independent information that there is no cloud present. Such ancillary information is available at the NSA/AAO CART site, where cloud data from both a cloud lidar and a $35 \mathrm{GHz}$ cloud radar are available.

In the following we present a simulation of PWV retrieval uncertainties for a collection of high latitude atmospheric profiles based upon the retrieval algorithm. First we discuss the details of the retrieval algorithm and then the uncertainty in retrieved PWV using a number of different channel combinations for the case of clear-sky conditions.

\section{1) RETRIEVAL ALGORITHM}

We use a Newtonian iteration (Rodgers 1976) to retrieve the atmospheric state vector 


$$
\mathbf{x}=\left(\begin{array}{c}
\boldsymbol{\rho}_{\mathbf{v}} \\
\mathrm{LWP}
\end{array}\right)
$$

from a vector of TB measurements at various frequencies $\left(f_{i}\right)$ :

$$
\mathbf{y}=\left(\begin{array}{c}
T B\left(f_{1}\right) \\
\cdots \\
T B\left(f_{k}\right)
\end{array}\right) .
$$

Here $\rho_{v}$ is a vector describing the moisture state. Although later we use lidar to discriminate cloudy conditions, for generality, here we present an algorithm that solves for cloud liquid water path. Two versions of the algorithm have been employed in this study. In the first "simple" scheme, the humidity is described by a single value of PWV and the water vapor profile is assumed to be a scaled version of a first guess or background profile. This is acceptable for retrievals using the lower frequency channels when the opacity of the lower atmosphere is low. In the second "full" scheme, water vapor is carried as the logarithm of water-vapor mixing ratio on $\mathrm{N}$ discrete levels and the vertical shape of the water-vapor profile is allowed to evolve during the retrieval process. This is more appropriate for retrievals using the $183 \mathrm{GHz}$ channels where the brightness temperature is sensitive to the emission temperature of the water vapor. The logarithm is used since the mass mixing ratio may sensibly vary by several orders of magnitude and carries with it the advantage that it does not allow negative values of mixing ratio to be retrieved. It should be noted that the primary driver for using this approach is to improve the resultant PWV value rather than derive a water vapor profile.

The $(n+1)$ th iterate of the atmospheric state $\mathbf{x}_{n+1}$ is calculated from the previous iterate $\mathbf{x}_{\mathbf{n}}$ and a first guess $\mathbf{x}_{0}$ using:

$$
\mathbf{x}_{n+1}=\mathbf{x}_{0}+\mathbf{W}_{n}\left\{\mathbf{y}-\mathbf{y}_{n}-\mathbf{H}_{n}\left(\mathbf{x}_{0}-\mathbf{x}_{n}\right)\right\},
$$

where $y_{n}$ is the forward-modeled TB vector corresponding to the atmospheric state $x_{n}$ and $\mathbf{H}_{n}=\partial \mathbf{y}_{n} / \partial \mathbf{x}_{n}$ is the Jacobian of the forward model. The estimation operator $\mathbf{W}_{\mathbf{n}}$ is defined by

$$
\mathbf{W}_{n}=\mathbf{B H}_{n}{ }^{\mathrm{T}}\left(\mathbf{H}_{n} \mathbf{B H}_{n}{ }^{\mathrm{T}}+\mathbf{R}\right)^{-1}
$$


where $\mathrm{T}$ is the matrix transpose operator, $\mathbf{B}$ is the covariance matrix of the background field and $\mathbf{R}$ is the observation error covariance matrix given by the sum of the forward model $\mathbf{F}$ and instrument measurement $\mathbf{E}$ error covariance matrices.

Equation (3) is applied iteratively until satisfactory convergence is reached. At convergence, the covariance matrix of the solution $\mathbf{x}_{\infty}$ is given by:

$$
\mathbf{S}_{\infty}=\left(\mathbf{B}^{-1}+\mathbf{H}^{\mathrm{T}} \mathbf{R}^{-1} \mathbf{H}\right)^{-1},
$$

where $\mathbf{H}$ is the value of $\mathbf{H}_{n}$ at convergence. The uncertainty of the retrieved PWV (determined by integrating $\boldsymbol{\rho}_{\mathrm{v}}$ with respect to height) and LWP are obtained from $\mathbf{S}_{\infty}$. We note that the above derivation makes the assumption that all of the error terms are Gaussian random variables. Also, Eq. (5) assumes that the problem is linear in the general region of $\mathbf{x}_{0}$ and $\mathbf{x}_{\mathrm{n}}$, the result of which is a slight underestimation of the retrieval errors.

In both versions of the algorithm, the background field is provided by a representative radiosonde profile $\rho_{\mathrm{v}}$ discretized at $\mathrm{N}$ atmospheric levels. The background temperature and pressure profiles remain fixed during iteration, and $\mathbf{H}_{n}$ is evaluated by forward modeling the effect on TBs of water-vapor perturbations, either scaled through the entire profile (simplified scheme) or individually in each of the $\mathrm{N}$ model levels, and liquid water perturbations within model layers demonstrating $>95 \%$ relative humidity. After each iteration, water vapor is redistributed away from supersaturated layers to adjacent ones, following Prigent et al. (1994). The final solution for $\boldsymbol{\rho}_{\mathrm{v}}$ is integrated to obtain PWV. For the retrieval to function, realistic values of $\mathbf{B}$ and $\mathbf{R}$ must be used. In the simple retrieval scheme, we chose B such that the covariance of $\boldsymbol{\rho}_{\mathrm{v}}$ and LWP encompass the entire range of possible values; in the full scheme 7 years of March radiosonde observations at Barrow are used to determine the climatological covariance of the log mass mixing ratio which is taken as a proxy for the humidity elements of the error covariance B. In both schemes, these choices of $B$ give the background little statistical 
weight in the final solution, although in the latter the term $\mathbf{B H}_{n}$ constrains the way in which water vapor is redistributed in the vertical.

The determination of $\mathbf{R}$ is somewhat more involved. Separating $\mathbf{R}$ into its component parts, we must consider both an instrument error and a forward-model error. We can assume these errors to be adequately modeled by Gaussian random processes. We consider the instrument error $\mathbf{E}$ to describe the uncertainty in the radiometer measurement including both random and systematic sources of error. The forward-model error contributions must describe any effects that are not represented in the retrieved parameters. This includes, but is not restricted to, absorption coefficient errors, cloud and water-vapor height assignment errors (most significant if the simple scheme is used with $183 \mathrm{GHz}$ channels), uncertainty in the background temperature and/or pressure profiles, forward model discretization error, and other effects not modeled such as horizontal inhomogeneities. Although, ice clouds can impart significant forward model variations, in this study we restrict our analysis to those times when the lidar indicated that no clouds were present.

\section{2) SIMULATIONS OF RETRIEVAL UNCERTAINTIES USING VARIOUS COMBINATION OF FREQUENCIES}

We employed the "simple" retrieval algorithm described above to evaluate the uncertainty in retrieving PWV using a variety of frequency combinations. We assumed that the retrieval has successfully converged and that the background has no weight in the final answer; thus $\mathbf{B}^{-1}$ in (5) is a matrix of zeroes. The PWV and LWP errors are then estimated for a set of realistic highlatitude model profiles simply from the right-hand term of (5) without actually performing the retrieval. We selected four combinations of channels that demonstrate the contribution that each additional set of frequencies offers to the retrieval. The choice of channels was prompted by two existing instruments; the DOE Microwave Water Radiometer (MWR), which operates with channels at 23.8 and $31.4 \mathrm{GHz}$, and the NASA Millimeterwave Imaging Radiometer (MIR) flown on the NASA ER-2 high altitude aircraft with double sideband channels at $89,150,183.31 \pm 1, \pm 3, \pm 7,220$ and $340 \mathrm{GHz}$ (Racette et al. 1996). The MWR was designed for ground-based operation and we have assumed a combined instrument and modeling uncertainty equivalent to $1 \mathrm{~K}$ in zenith- 
viewing mode. Ground-based calibration of the MIR is more challenging and this, combined with a potentially larger forward-modeling error associated with increased sensitivity to atmospheric constituents, has led us to assume a $3 \mathrm{~K}$ uncertainty for the MMW channels. It should be noted that where $183 \mathrm{GHz}$ channels are used in our simulation, we use the average of the lower and upper sidebands in the forward-model calculations. In all cases we assume that errors are uncorrelated, thus $\mathbf{R}$ is a diagonal matrix.

The four different channel combinations are:

1. $\quad$ MWR (i.e. 23.8 and $31.4 \mathrm{GHz}$ )

2. $\quad 3 \times 183.31 \mathrm{GHz}$ (i.e. $183.31 \pm 1, \pm 3, \pm 7$ ) $\mathrm{GHz}$

3. $3 \times 183.31 \mathrm{GHz}+89 \mathrm{GHz}$

4. $3 \times 183.31 \mathrm{GHz}+89 \mathrm{GHz}+\mathrm{MWR}$.

The range of model profiles is provided by a representative set of 400 clear-air high latitude model atmospheres that have a PWV range of 0.3 to $35 \mathrm{~mm}$. Simulations that have been performed using cloudy profiles are not included herein. The results for the cloudy profiles may be found in Jones and Racette (1998). Though the model profiles used here contain no cloud, the error covariance matrix computed is based upon a twoparameter retrieval, i.e., PWV and LWP.

Fig. 4 shows the percentage PWV retrieval uncertainty for the 400 profiles as a function of PWV using each of the four channel combinations. The MWR-only performance clearly demonstrates a reciprocal relationship between percentage uncertainty and PWV. Absorption by both cloud and water vapor at these frequencies is relatively weak; therefore across the entire range of PWV values (and indeed up to much moister values), the channels do not lose their absolute sensitivity to changes in PWV. However, for low PWV, small errors in TB result in large relative PWV errors. The three $183 \mathrm{GHz}$ channels show a very high level of skill below about $3 \mathrm{~mm}$ of water vapor, but quickly become saturated as the humidity increases which causes the combination to become ineffective by $10 \mathrm{~mm}$. The addition of the $89 \mathrm{GHz}$ channel, which lies in a nominal atmospheric window but which is affected by water-vapor continuum, extends the useful range of the MMW measurements to much higher PWV values. The best 
performance is obviously provided when all six channels are used. Although some contribution comes from the statistical advantage of having more channels, the major part of the improvement is due simply to the fact that significant sensitivity to changes in PWV is present in at least one of the channels at any value of PWV. While LWP retrieval error results have not been shown here, not surprisingly the six-channel combination outperforms the others in this respect also (Jones and Racette 1998).

These theoretical results motivated the further investigation of the utility of ground-based MMW measurements through experimental studies.

\section{NSA experiment}

Based upon the above studies, an experiment was conducted to investigate the utility of MMW measurements for making ground-based estimates of PWV during the very cold and dry conditions that predominate during the winter months in high-latitude regions. The National Aeronautics and Space Administration's Goddard Space Flight Center (NASA/GSFC) and the National Oceanic and Atmospheric Administration's Environmental Technology Laboratory (NOAA/ETL) deployed a suite of radiometers covering 25 channels in the frequency range of $20 \mathrm{GHz}$ up to $340 \mathrm{GHz}$. Nearly consecutive radiometer data were collected for 23 days during March 1999 at the DOE ARM program North Slope of Alaska/Adjacent Arctic Ocean Cloud and Radiation Testbed site (DOE ARM NSA/AAO CART) located at N71 ${ }^{\circ} 19.378^{\prime}$, W156 $36.934^{\prime}$ just outside Barrow, Alaska. Table 1 summarizes the MMW radiometers and the measurement channels deployed for the experiment. A description of the operational ARM instruments at the NSA/AAO may be obtained at the web site www.arm.gov.

The radiometers were set up adjacent to one another and oriented to scan from east to west across the sky. The Circularly Scanning Radiometer (CSR) and O2 Scanning Radiometer scanned $360^{\circ}$. Details of the operation and calibration of the $\mathrm{O} 2$ Scanning Radiometer can be found in Westwater et al. (1999). The CSR is an instrument specifically designed for the NSA experiment. The CSR completes one scan cycle every $120 \mathrm{~s}$ during which time a $120^{\circ}$ sector of the sky is scanned and two blackbody calibration references are observed; one reference is heated to $\sim 330 \mathrm{~K}$ while the other was maintained at the outside ambient temperature. Due to the long period between 
calibrations, a reference differencing technique was employed. The MMW channels used a chopping wheel to alternatively observe an internal reference and the scene. The MW channels used ferrite switches to switch between the scene and an internal reference. Problems discovered with the ferrite switches after the experiment made the calibration of the MW channels suspect. Therefore, these data are not included in the present analysis. Also, the $325 \mathrm{GHz}$ data are not included in this analysis due to excessive noise in the data. The tipping curve calibration technique (tip-cal) was applied to the following CSR channels: $183+/-7,183+/-12,183+/-15,340 \mathrm{GHz}$. The tip-cal was not applied to the $183 \pm 0.5,183 \pm 1,183 \pm 3$, and $183 \pm 5 \mathrm{GHz}$ channels due to the higher opacity of these frequencies. The application and limitations of the tip-cal technique can be found in Han and Westwater (2000).

The DOER and the MIR had obscured views to the west and thus their scan elevation angle was limited from $70^{\circ}$ toward the west to $20^{\circ}$ toward the east. The obscured view limited our ability to apply tipping calibration corrections to these data. A description of the DOER may be found in Racette et al. (1998). The cold weather affected the performance of the sensor that measures the elevation angle; thus the ability to apply the tip-cal to the DOER data was severely compromised. These data are not included in the present analysis. The MIR instrument has a long heritage of making brightness temperature images from onboard the NASA high altitude ER-2 aircraft. A description of the MIR instrument, its operation and calibration can be found in Racette et al. (1996). The instrument uses two blackbody calibration references to achieve absolute calibration; one reference is heated to $\sim 328 \mathrm{~K}$, while the other is allowed to float at the ambient temperature. Studies performed on the calibration of the MIR indicate the uncertainty in brightness temperature is $\sim 2 \mathrm{~K}$ for all the channels for TB measurements between 200 and $300 \mathrm{~K}$. For TBs lower than $200 \mathrm{~K}$ the uncertainty of the measurements degrades due to extrapolation of the calibration data. Calibration studies with the instrument have revealed a source of calibration error due to limitations of the beam efficiency which is accentuated at lower TBs (Racette et al. 1995). This effect is most significant for the $89 \mathrm{GHz}$ and $150 \mathrm{GHz}$ channels. For this reason, the tip-cal technique was applied to these two channels. 
The tip-cal technique was not applied to the other MIR channels because the other channels measure higher TBs, the uncertainty in the measurement of the elevation scan angle, and the inability to perform a symmetric (with respect to zenith) scan.

Over the duration of the experiment, 10 sets of calibration measurements were performed using the MW radiometers deployed for this experiment. Each set of calibration measurements consisted of views of three blackbody references. One blackbody was stored outside, and therefore its measured temperature was very close to that of the outside air temperature. The second blackbody was stored inside a heated shelter. Its temperature was approximately $295 \mathrm{~K}$, and it was observed to slowly decrease during the interval that the calibration measurements were made. The third blackbody was immersed in liquid nitrogen. These 10 sets of measurements were not used to apply any correction to the collected data but were used instead to study the stability and uncertainty in the brightness temperature measurements.

During the experiment, the CART site operated a full suite of atmospheric remote-sensing instrumentation (Stamnes et al. 1999). For the present analysis, we have made extensive use of the Microwave Radiometer (MWR), Väisälä Ceilometer, and surface meteorological measurements from the $60-\mathrm{m}$ tower. In addition to the usual CART site instrumentation the NOAA Depolarization and Backscatter Unattended Lidar (DABUL), the State University of New York Rotating Shadowband Spectroradiometer (SUNY RSS) and other surface based meteorological instrumentation were deployed during the intensive observation period. Väisälä HUMICAP RS-80 type radiosondes (ARM) were launched daily at the CART site. At the nearby National Weather Service station in Barrow, radiosondes (NWS) with VIZ resistive humidity sensors were launched twice daily. Both the VIZ radiosondes (Wade 1994) and the Väisälä RS80 radiosondes can have problems accurately measuring low amounts of water vapor. Five radiosondes with chilled-mirror humidity sensors were also launched during the observation period. The chilled-mirror measurements were intermittent and often contained suspect humidity values. Therefore, the chilled-mirror measurements are not considered in the present study. 


\section{a. Observations}

The experiment benefited from a wide variety of Arctic winter atmospheric conditions ranging from clear and calm skies to blowing snow and heavy multilayer cloud coverage. Figure 5a shows the data obtained from the cloud ceilometer during the experiment. The periods during which the ceilometer recorded clear sky conditions are indicated by the symbols at $5000 \mathrm{~m}$. Also on the same plot is the temperature measured near the surface. The near-surface temperature varied between about $-42^{\circ} \mathrm{C}$ and $-18^{\circ} \mathrm{C}$ over the course of the experiment. Measurements of PWV made by the CART site MWR are shown in Fig. 5b. As shown, the PWV varied from $\sim 0.8$ to $\sim 5.7 \mathrm{~mm}$ during the experiment. The driest conditions were experienced during periods of clear skies. Two periods of prevailing clear skies occurred during the experiment, on Julian days $67-71$ and $85-89$. During these times the PWV was $\sim 2 \mathrm{~mm}$ or lower. During the first period the surface temperature was $\sim 10^{\circ} \mathrm{C}$ colder than during the later period although the PWV was about the same. Cloudy conditions with occasional snow were prominent during Julian days $72-84$.

The PWV calculations based upon the NWS (circles) and ARM (squares) radiosonde measurements are overlaid on Fig. $5 \mathrm{~b}$. Because of the known problems associated with aging of the HUMICAP RS-80 humidity sensors, we applied the Väisälä correction algorithm (Lesht 1999) to the measurements. The PWV values from the original are somewhat drier than those made from the corrected profiles. The maximum difference between the original and corrected PWV is $0.6 \mathrm{~mm}$. In this study we present results using only the corrected profiles.

Fig. $5 \mathrm{c}$ shows TB measurements made by the MIR over the duration of the experiment. Forward-model TB calculations derived from radiosonde measurements are indicated by symbols; the NWS and ARM RAOBS are indicated with circles and squares, respectively. Forward model calculations were made using the most recent absorption model published by Rosenkrantz (1998). Significant differences between the forwardmodeled TBs and those measured by the MIR are observed for all the radiosonde calculations. The TB measurements made near the $183 \mathrm{GHz}$ absorption line are generally lower than the forward modeled TBs; whereas, in the window regions near $150 \mathrm{GHz}, 220$ $\mathrm{GHz}$, and $340 \mathrm{GHz}$, the measured TBs are higher than the forward-modeled brightness 
temperatures. Thus, the discrepancies between the forward-modeled and measured TBs cannot be explained by a simple bias of the radiosonde humidity profile.

Significant response of the MMW channels to the presence of clouds can be seen in the line plots of Fig. $5 \mathrm{c}$ between Julian days 72 and 84 . Images produced by the window channels of the scanning radiometers during these times of cloudy conditions (not shown in this paper) demonstrate the potential of MMW radiometry for studies of arctic clouds. In this study, however, we limit our analysis to modeling and estimating PWV during clear conditions.

A time-series comparison of data from the MIR and CSR is shown in Fig. 6. The data are shown from the last four days of the experiment when the prevailing meteorological conditions were clear, dry, and cold. The brightness temperatures from the CSR are shown as blue lines with the channels indicated on the right-hand side. Also shown are the forward-modeled TBs based on the NWS and ARM radiosondes (same as in Fig. 5c). The MIR TB measurements are plotted as colored lines with the channels indicated on the left-hand side of the figure. The MIR and CSR data have been averaged to the same time scale. The noise on the MIR data is less than on the CSR data due to the better radiometric resolution and more frequent sampling of the MIR measurements. The consistency of the measurements from all the channels is apparent. The four channels that the two instruments have in common nearly overlie one another. The average difference between the CSR and MIR brightness temperatures (CSR - MIR) are 2.02, -2.25, 0.18, and $0.45 \mathrm{~K}$ for the $183+/-1,183+/-3,183+/-7$, and $340 \mathrm{GHz}$ channels, respectively. Discrepancies at the $183+/-1$ and $183+/-3 \mathrm{GHz}$ channels can partly be explained by small passband response differences. Previous calibration studies made using the MIR, studies using the tip-cal technique, the 10 sets of measurements made using the three blackbody references, and the comparison of the independently calibrated measurements lead us to a conservative estimate of the calibration uncertainty of $+/-3 \mathrm{~K}$ for all the channels over the range of brightness temperatures observed throughout the experiment, except for the 89 and $150 \mathrm{GHz}$ channels. The uncertainty of the $89 \mathrm{GHz}$ and $150 \mathrm{GHz}$ channels is somewhat greater ( $+/-5 \mathrm{~K}$ for TBs less than $40 \mathrm{~K}$ ).

For the periods of clear sky, the MWR channels exhibited a dynamic range not exceeding $3.5 \mathrm{~K}$, whereas the MMW channels exhibited responses in excess of $50 \mathrm{~K}$ over 
the same period. The greater response to changes in precipitable water vapor is demonstrated by closer examination of the measured brightness temperatures made during one clear day. Fig. 7 shows brightness temperature fluctuations measured by the MIR and MWR on Julian day 70. The brightness temperatures measured at 5 GMT are subtracted from the measurements made over the remainder of the day. The measurements made by the MWR change by no more than $1 \mathrm{~K}$ over this interval, whereas, brightness temperature fluctuations of the MMW channels were 10 to 20 times greater. The MWR is remarkable in that it can yield reliable estimates and track changes in low PWV even though the dynamic range of its signals is so small. However, as illustrated by the analysis of Section 2.b.2), the uncertainty of low PWV estimates based upon MWR measurements is extremely sensitive to relatively small errors in calibration. This fact was demonstrated by the discovery of calibration-based errors in the MWR data and is discussed in the next section.

\section{Analysis and discussion}

a. MWR calibration issues

Comparisons of retrieved PWVs were made using measurements from the MWR and the MIR and CSR $183+/-7 \mathrm{GHz}$ channels. The MIR-based retrievals were made using the "full" iterative physical retrieval described in Section 2.b.1), whereas the CSRbased retrievals were performed using a non-iterative statistical retrieval technique (Westwater 1993). Both the MIR- and CSR-based $183+/-7 \mathrm{GHz}$ retrievals agree exceptionally well, even though they used two independently calibrated datasets and fundamentally different retrieval algorithms. However, we discovered significant differences in the MWR retrieved values and those derived from the CSR and from the MIR. These differences existed not only in the magnitude of the values but also in the hourly trends of the time series. The discrepancies led us to examine the calibration technique used with the MWR instrument.

The MWR calibration is based in part upon the apparent brightness temperature of an internal noise diode. The noise temperature of this diode is adjusted to be consistent with tip-cal measurements. In the original calibration algorithm, tip-cal measurements averaged over several hours were used to adjust the noise temperature of the diode 
(Liljegren 2000). By eliminating the averaging and using the "instantaneous" tip-cal measurement to adjust the noise diode temperature (Cimini et al. 2003, Han and Westwater 2000), a dramatic improvement in the consistency of the measurements in all three instruments is achieved. Fig. 8a shows the TB measurements of the two MWR channels before and after modification to the calibration algorithm. The modified data are clearly less noisy, differing from the original brightness temperatures by as much as $2 \mathrm{~K}$. We note that over the entire month of clear-air data, the total range of the $23.8 \mathrm{GHz} \mathrm{TB}$ data was $\sim 3.5 \mathrm{~K}$, so that a $2 \mathrm{~K}$ calibration error can lead to significant error in retrieved PWV. In Fig. $8 \mathrm{~b}$ the MWR-based retrievals using the original and modified calibrations are shown (the modified MWR TB data is also used to estimated the PWV in Fig. 5b). Corrections to the retrieved PWV are seen to exceed $100 \%$ at certain times, e.g. between Julian day 68 and 69.

\section{b. Model comparisons}

Westwater et al. (1990) performed a study in which MW TBs were calculated from contemporary absorption models and then compared with well-calibrated radiometer measurements. Since then, several new models have been developed. However, the original model of Liebe and Layton (1987) has still proven to be an excellent one, and we use it as one of our candidate models. For simplicity, we refer to the model as L87. This model is very close, but not identical, to the model published by Liebe (1989). Based on measurements not available in 1987, Liebe et al. (1993) updated the L87 model, and made several modifications to the water-vapor continuum, the $\mathbf{2 2 . 2 3 5}$ $\mathrm{GHz}$ water-vapor line parameters, and the $5-\mathrm{mm} \mathrm{O} 2$ band parameters. We refer to this model as L93. Finally, Rosenkranz (1998) made additional modifications to L87 and L93. This model (ROS) is the most contemporary that we consider.

To study the behavior of the three models as a function of frequency, we selected a cold, dry profile measured during the experiment $(P W V=0.8 \mathrm{~cm})$, and then extrapolated the profile above its highest level $(\sim 20 \mathrm{mb})$ to a level of $0.1 \mathrm{mb}$. The entire profile had a total of 413 levels from the surface at $1028.2 \mathrm{mb}$ to the upper level of 0.1 mb. The calculated zenith-viewing TBs from $1 \mathrm{GHz}$ to $350 \mathrm{GHz}$ are shown in Fig. 9a. It is apparent that there are substantial differences among the models in some parts of the 
spectrum, especially above $200 \mathrm{GHz}$, where the L93 departs significantly from the other two. Changes in line parameters and different continuum formulations account for these differences. The differences among the three models are more apparent in Fig. 9b; here we show the computed model differences from L87 using the same profile. Differences between the models exist, not only in the window regions, but also around the water vapor lines at $183.31 \mathrm{GHz}$ and $325 \mathrm{GHz}$. These differences can be as large as $10 \mathrm{~K}$. To illustrate the apparent differences around the $60 \mathrm{GHz} \mathrm{O} 2$ band and the $118 \mathrm{GHz} \mathrm{O} 2$ line, we computed the differences for the same profile, but with the humidity set to zero. As shown in Fig. 9c, significant changes in the $\mathrm{O} 2$ line parameters and interference coefficients exist in these models.

\section{c. Retrieval of temperature profiles using O2 Scanning Radiometer data}

Data from the $60 \mathrm{GHz}$ O2 Scanning Radiometer were used to derive temperature profiles of the lower troposphere (Leuski and Westwater 2000). For the data we present here, we used temporally interpolated radiosondes as a first guess for our retrieval. The interpolation time step was $15 \mathrm{~min}$ and a vertical height grid of $30 \mathrm{~m}$ was selected for retrievals up to $1500 \mathrm{~m}$. The initial guess was used in the linear retrieval method of Tikhonov -Twomey (Tikhonov and Arsenin 1977; Twomey 1977). The surface temperature, as measured by the instruments on the meteorological tower at the CART site, is used as the initial value of the retrieval, and variations at horizontal viewing are used to determine gain calibration of the $\mathrm{O} 2$ Scanning Radiometer. A time-height cross section of the $60 \mathrm{GHz}$ temperature profile retrievals is shown in Fig. 10. A great deal of structure in the temperature profile is revealed in the figure. Particularly evident is strong diurnal dependence on the temperature inversion near the surface. These temperature profiles obtained from the $\mathrm{O} 2$ Scanning Radiometer data are used in the PWV retrievals discussed in the next section.

\section{d. Clear-sky comparisons of retrieved PWV}

Single-channel PWV retrievals were performed using the six channels of the MIR data for periods of clear conditions. The results are shown in Fig. 11. The "full" retrieval algorithm described in section 2.b.1) was used. The forward model used was ROS. The results shown are based upon a single parameter, i.e., PWV. The results presented are 
limited to the period of predominantly clear conditions between Julian days 85 and 89; only those times in which the ceilometer recorded clear-sky conditions over a 10-minute interval are included in the figure. The PWVs calculated from data of the ARM Väisälä RS-80 radiosondes are overlaid on the retrieved values. Discrepancies as large as $100 \%$ exist between retrieved values obtained using various channels. The $220 \mathrm{GHz}$ channel and the MWR-based (using both the $23.8 \mathrm{GHz}$ and $31.4 \mathrm{GHz}$ channels) retrieved values consistently yield the highest values of PWV, whereas the retrieved values for the $183+/$ 1 and $183+/-3 \mathrm{GHz}$ consistently yield the lowest retrieved PWV values. The $183+/-7$ $\mathrm{GHz}$ and $340 \mathrm{GHz}$ retrievals agree very well with each other. The differences in the retrieved values are consistent with the discrepancies in the forward-modeled TBs based upon the RAOBs and the measured TBs shown in Fig. 5c. The window channels yield higher estimates of PWV, while the measured TBs are greater than those of the forwardmodel calculations. The converse is true for the channels nearest the peak of the $183 \mathrm{GHz}$ absorption line.

Also shown in Fig. 11 are comparisons of the retrieved PWV derived from solar absorption measurements made using the RSS. The RSS retrieval takes advantage of the differential absorption due to water vapor in the $940 \mathrm{~nm}$ spectral regions. The atmosphere is assumed to be horizontally homogeneous to obtain estimates of the PWV along a zenith path. The RSS retrieval technique and results are presented by Kiedron et al. (2001). Good consistency (correlation 0.95) is achieved between the RSS-based retrievals and those obtained using the MW and MMW measurements. The RSS retrievals fall between the retrievals from $183 \pm 3 \mathrm{GHz}$ and $183 \pm 7 \mathrm{GHz}$ MIR channels with an average bias of $-0.205 \mathrm{~mm}$ and $+0.120 \mathrm{~mm}$, respectively.

Single-channel retrievals were also performed using the L93 and L87 models. The differences we found in the retrieved values between channels are comparable to the differences obtained when using the ROS model, albeit the absolute values in the retrievals differ in a manner predictable from the differences between models in the forward-modeled TBs. A statistical comparison of the forward-modeled TBs with the measurements is presented in the next section. Multichannel retrievals were also performed using all three models. The results of the multichannel retrievals take the form 
of a weighted average of the same single-channel retrievals. These results add little to the discussion of the observed discrepancies and therefore are not presented.

The 7-year data set used to derive the curves in Fig 3 were used to calculate the response of each channel to small changes in PWV. The data were fit to a linear model for values of PWV between 0.5 and $1.5 \mathrm{~mm}$. A linear response is a reasonable approximation over this small interval; however, due to the highly nonlinear PWV-TB relationship, the calculated slopes are somewhat sensitive to the range over which the linear model is fit. The calculated slopes in $\mathrm{K} / \mathrm{mm}$ are $1.25,0.34,1.81,6.95,78.6,75.0$, $39.2,14.6,44.5$ for the $23.8 \mathrm{GHz}, 31.4 \mathrm{GHz}, 89 \mathrm{GHz}, 150 \mathrm{GHz}, 183.31+/-1 \mathrm{GHz}$, $183.31+/-3 \mathrm{GHz}, 183.31+/-7 \mathrm{GHz}, 220 \mathrm{GHz}, 340 \mathrm{GHz}$, respectively. If a $3 \mathrm{~K}$ instrument error is assumed ( $0.3 \mathrm{~K}$ error for the $23.8 \mathrm{GHz}$ and $31.4 \mathrm{GHz}$ channels), the corresponding error in PWV (in mm) would then be $0.24,0.87,1.66,0.43,0.038,0.040$, $0.076,0.205,0.067$ for the channels as listed above. The differences in the retrieved PWV shown in Fig. 11 are significantly greater than can be explained from instrument error alone.

e. Statistical comparisons of absorption models using forward modeled TBs from the $R A O B$ soundings and measured TBs

Using the Väisälä ceilometer to identify cloud-free conditions within $\pm 30 \mathrm{~min}$ of radiosonde release time, a total of 18 NWS and 9 corrected ARM RS-80 soundings were determined to be cloud free. Forward-modeled TBs from the three models were calculated using these radiosonde profiles. In Table 2, we show statistical comparisons between the calculations and near-concurrent TB measurements. The TB measurements were averaged over a one-hour period centered about the time of the radiosonde launch. It is apparent that if the corrected ARM RAOBS and the NWS RAOBS are more representative of atmospheric truth, then the L93 model TBs are considerably higher than the MIR observations at $183 \pm 7 \mathrm{GHz}, 220 \mathrm{GHz}$, and $340 \mathrm{GHz}$. However, the L93 model is the best match for the MWR $23.8 \mathrm{GHz}$ and $31.4 \mathrm{GHz}$ channels. All three models differ by as much as $0.55 \mathrm{~K}$ and $0.82 \mathrm{~K}$ at $23.8 \mathrm{GHz}$ and $31.4 \mathrm{GHz}$, respectively. In general the differences between the L87 and ROS models are close in magnitude, although the differences are significant for some channels, e.g. $31.4 \mathrm{GHz}$. The TB differences for the 
$183 \pm 1 \mathrm{GHz}$ and $183 \pm 3 \mathrm{GHz}$ channels are conspicuously large, much larger than can possibly be explained by radiometer measurement error. The differences between the NWS and ARM statistics for the $183 \pm 1 \mathrm{GHz}$ and $183 \pm 3 \mathrm{GHz}$ channels can be attributed to differences in the local conditions where the radiosondes were launched. Local heating and sources of water vapor within the city of Barrow where the NWS radiosondes were launched could result in increased values of calculated TBs. The associated large standard deviations and relative small sample size limits the statistical significance of the difference between these models. Furthermore, the uncertainties in the RAOB measurements of water vapor, together with the uncertainties in the MIR and CSR calibrations of $\sim 3 \mathrm{~K}$, do not allow us to make a definitive statement regarding which of the $\mathrm{L} 87$ and ROS models is better.

\section{Conclusion}

Accurate measurement of water vapor during dry conditions is important for modeling the radiation budget in polar regions. Based on a history of radiosondes launched by the National Weather Service (NWS) at Barrow, Alaska, we found that dry conditions at Barrow are prevalent over a substantial fraction of the year. A probability distribution of PWV constructed using these radiosondes shows that there is a high percentage of cases $(\sim 50 \%)$ in which PWV is less than $5 \mathrm{~mm}$, i.e., those cases in which $183 \mathrm{GHz}$ radiometry is promising. In this paper we evaluated theoretically the potential of MMW radiometry for measuring low amounts of PWV, presented experimental data, and pointed out the difficulties associated with such measurements.

Weighting function analysis shows the greatly enhanced sensitivity of the 183 $\mathrm{GHz}$ region to water vapor at low concentrations (PWV $<5 \mathrm{~mm}$ ); at higher concentrations ( $\mathrm{PWV}>10 \mathrm{~mm}$ ), the sensitivity of measurements made using the 23 and $31 \mathrm{GHz}$ channels is adequate to retrieve PWV to better than $5 \%$ uncertainty. A combination of MW and MMW measurements yields adequate sensitivity over the entire range of PWV expected in the polar regions. The weighting functions near the $183 \mathrm{GHz}$ channels, especially for PWV $>2 \mathrm{~mm}$, show a non-negligible dependence on temperature. The use of either $\mathrm{RAOBs}$ or $60 \mathrm{GHz}$ radiometer temperature-profile measurements improves the accuracy of the $183 \mathrm{GHz}$ retrievals. We have described a 
flexible retrieval algorithm for LWP and PWV from ground-based measurements. Using a collection of representative atmospheric profiles, we have simulated the expected retrieval performance of various channel combinations for conditions that are experienced at higher latitudes. The results show, that in the absence of ice cloud, a combination of channels from 23 to $183 \mathrm{GHz}$ can yield very accurate estimates (uncertainties $<5 \%$ ) of PWV in very dry to moist atmospheres. These results are consistent with the weighting function analysis. This study indicates that the channels centered about the $183 \mathrm{GHz}$ absorption line together with the existing MWR channels could provide complete measurement coverage for all of the PWV conditions encountered at Barrow.

The NASA/GSFC and NOAA/ETL deployed a suite of radiometers covering the spectral range from 20 to $340 \mathrm{GHz}$. High-quality radiometric measurements were made over a 23-day period between 7 March through 30 March, 1999. Two radiometer systems with redundant channels were independently calibrated. The NOAA/ETL radiometer used the tip-cal technique, while the NASA/GSFC MIR system used hot and ambient calibration references to achieve calibration, with the exception of the $89 \mathrm{GHz}$ and $150 \mathrm{GHz}$ channels, which used the tip-cal. Data from the redundant channels were in basic agreement.

Several very cold, dry, and clear days have been analyzed and, on a daily basis, these data show substantial fluctuations in the MMW brightness temperatures (some 25 to $30 \mathrm{~K}$ ), while corresponding variations in the ARM MWR were less than $0.5 \mathrm{~K}$. During cloud-free conditions observed over the experiment, the range of TB variations for the MWR was $3.5 \mathrm{~K}$; over the same interval, the range of TB from the $183 \pm 7 \mathrm{GHz}$ channel was $70 \mathrm{~K}$.

Initial PWV comparisons derived from MMW measurements and from measurements made by the two MWR systems showed large discrepancies. Upon closer examination, the discrepancies were attributed to calibration errors in the MWR, some as large as $2 \mathrm{~K}$. Application of the Han and Westwater (2000) calibration algorithm for the MWR yielded much better agreement between the MWR and MMW PWV measurements. 
Comparisons of contemporary absorption models show that substantial differences exist among them. The differences in these absorption models represent a substantial fraction of the error in retrieved PWV values. Determining an adequate model will provide substantial benefit to remote sensing by MMW radiometry. Comparisons of forward-modeled brightness temperature calculations based on radiosonde profiles and radiometer measurements show significant differences. For the MWR channels, the Liebe et al. (1993) model agreed best with the measurements with better than $0.1 \mathrm{~K}$ bias and a standard deviation of better than $0.2 \mathrm{~K}$ root mean square. However, for the MMW channels, the Liebe et al. (1993) model significantly over predicted TB. The uncertainties in RAOB measurements of water vapor, coupled with MIR and CSR calibration uncertainties of $\sim 3 \mathrm{~K}$, did not allow us to make a clear choice between the Liebe and Layton (1987) and the Rosenkranz (1998) absorption models. The observed differences could be due to uncertainty in radiosonde data, absorption models, radiometer calibration or, most likely, a combination of these. Nevertheless, biases on the order of $15-20 \mathrm{~K}$ between the measured and modeled TBs necessitate examination of the accuracy of absorption models near the $183 \mathrm{GHz}$ absorption line.

Single-channel and multichannel retrievals were performed using a combination of MW and MMW data. Differences as large as $50 \%-100 \%$ in the retrieved PWV values are consistent with differences observed in the forward-model TB comparisons. These differences are attributed primarily to errors in the absorption model and to a lesser extent on errors in the background temperature field and radiometer calibration. Additional measurements and further refinement of experimental design are needed to quantify the error sources. Emphasis should be placed on reducing the uncertainty of the radiometer measurements and increasing the frequency of radiosonde launches at the experiment site.

Overall, the study shows that using $183 \mathrm{GHz}$ radiometers to improve MWR retrievals at low amounts of PWV is sound, with a roughly 25 fold-increase in dynamic range during very dry conditions. A variety of simulations and theoretical considerations all suggest that better than $5 \%$ percent accuracy can be obtained during clear conditions for the range of PWV expected in the polar regions. However, retrieval of PWV using 
MMW radiometric measurements is complicated by absorption model uncertainties as well as uncertainties in the radiometric measurements and background field.

Zenith brightness temperatures collected during the intensive observation period along with data documentation are available on the ARM archive (www.arm.gov).

Acknowledgments. The work presented in this paper was sponsored by the Environmental Sciences Division of the Department of Energy as a part of their Atmospheric Radiation Measurement Program, the NOAA Environmental Technology Laboratory, and the NASA Goddard Space Flight Center.

\section{FIGURES AND TABLES}

Figure 1: Probability and cumulative distribution functions for PWV derived from RAOBs at Barrow, AK (1990 - 1996).

Figure 2: Average vapor density and temperature weighting functions for three ranges of PWV. The absorption model used is Rosenkranz (1998).

Figure 3: Brightness temperature versus precipitable water vapor at several frequencies. Calculations were based upon the 7-year collection of RAOBs at Barrow, Alaska. The absorption model used is from Rosenkranz (1998).

Figure 4: The percentage uncertainty in retrieved PWV versus true PWV for a selection of clear high-latitude model atmospheres using the four different channel combinations. See text for a definition of the frequency combinations.

Figure 5: Observations made during the NSA experiment. (a) Ceilometer data indicating cloud-base height (light blue points), periods of clear-sky conditions are indicated by the blue points at $5000 \mathrm{~m}$, and near-surface temperature (green line). (b) PWV (line) as measured using MWR after calibration algorithm modification. PWVs are calculated from the NWS (circles) and ARM (squares) radiosondes. (c) Brightness temperatures measured by the MIR and MWR and forward-modeled TBs based on radiosonde measurements and the model published in Rosenkranz (1998). 
Figure 6: Comparisons of MIR and CSR TB measurements.

Figure 7: Brightness temperature differences measured by the MIR and the MWR on Julian day 70 .

Figure 8: (a) MWR TBs using original calibration algorithm and modified calibration algorithm. (b) PWVs derived from original and modified calibration measurements.

Figure 9: (a) Forward-modeled brightness temperatures using three different absorption models. (b) Differences in TBs of the L93 and ROS model with respect to L87. (c) Differences in the models for a dry $(\mathrm{PWV}=0)$ atmosphere.

Figure 10: Temperature time-height cross sections retrieved using the ETL $60 \mathrm{GHz} O 2$ Scanning Radiometer with a first guess derived from RAOBS.

Figure 11: Clear-sky single-channel PWV retrievals using a variety of MMW channels.

TABLE 1: Millimeterwave radiometers deployed during the Arctic winter experiment

\begin{tabular}{|l|l|}
\hline \multicolumn{1}{|c|}{ Radiometer } & \multicolumn{1}{|c|}{ Channels (GHz) } \\
\hline Millimeterwave Imaging Radiometer (MIR) & $89,150,183.31+/-1,183.31+/-3,183.31+/-7$, \\
& 220,340 \\
\hline DOE Multichannel Microwave Radiometer (DOER) & $20.735,21.485,22.235,22.985,23.735,36.5$, and \\
& 89.0 \\
\hline Scanning-O2 & 60.5 \\
\hline Circularly Scanning Radiometer (CRS) & $20.6,31.65,183+/-0.5,183+/-1,183+/-3,183+/-$ \\
& $5,183+/-7,183+/-12,183+/-15,325+/-1,325$ \\
& $+/-3,325+/-8,340$ \\
\hline
\end{tabular}


Table 2. Average and standard deviation of (Measured - Calculated) TB(K) for three absorption Models. Clear conditions determined from ceilometer. Measured data are 1-hr averages centered around NWS and ARM radiosonde release times. Bolded values indicate best agreement between measured and calculated values. Sample sizes: NWS RAOB=18; $A R M$ RAOB $=9$.

\begin{tabular}{|l|l|l|l|l|l|l|}
\hline MWR 23.8 & L87-AVG & L87-SDE & ROS-AVG & ROS-SDE & L93-AVG & L93-SDE \\
\hline NWS_RAOB & 0.55 & 0.19 & 0.17 & 0.19 & -0.11 & 0.19 \\
\hline ARM_RAOB & 0.54 & 0.41 & 0.17 & 0.38 & -0.12 & 0.38 \\
\hline MWR 31.4 & & & & & & \\
\hline NWS_RAOB & 0.82 & 0.09 & 0.28 & 0.09 & -0.01 & 0.09 \\
\hline ARM_RAOB & 0.81 & 0.11 & 0.26 & 0.10 & -0.03 & 0.10 \\
\hline MIR 90 & & & & & & \\
\hline NWS_RAOB & -1.03 & 0.31 & -1.72 & 0.32 & -0.51 & 0.32 \\
\hline ARM_RAOB & -0.95 & 0.53 & -1.65 & 0.46 & -0.49 & 0.46 \\
\hline MIR 150 & & & & & & \\
\hline NWS_RAOB & 0.65 & 1.55 & $\mathbf{0 . 3 1}$ & 1.69 & -3.52 & 1.69 \\
\hline ARM_RAOB & 0.53 & 1.26 & $\mathbf{0 . 2 3}$ & 1.15 & -3.69 & 1.15 \\
\hline MIR 220 & & & & & & \\
\hline NWS_RAOB & $\mathbf{3 . 1 4}$ & 2.57 & 4.15 & 2.58 & -6.82 & 2.58 \\
\hline ARM_RAOB & $\mathbf{2 . 4 3}$ & 3.00 & 3.47 & 2.68 & -7.54 & 2.68 \\
\hline MIR 340 & & & & & & \\
\hline NWS_RAOB & $\mathbf{0 . 4 1}$ & 5.65 & 0.69 & 5.70 & -15.86 & 5.70 \\
\hline ARM_RAOB & $\mathbf{0 . 6 5}$ & 5.67 & 0.93 & 5.24 & -15.07 & 5.24 \\
\hline
\end{tabular}

Table 2 (continued)

\begin{tabular}{|l|l|l|l|l|l|l|}
\hline MIR 183+/-7 & L87-AVG & L87-SDE & ROS-AVG & ROS-SDE & L93-AVG & L93-SDE \\
\hline NWS_RAOB & -3.62 & 4.68 & $\mathbf{1 . 2 4}$ & 4.79 & -10.14 & 4.79 \\
\hline ARM_RAOB & -4.61 & 6.12 & $\mathbf{0 . 2 3}$ & 5.21 & -10.98 & 5.21 \\
\hline MIR 183+/-3 & & & & & & \\
\hline NWS_RAOB & -16.71 & 8.82 & $\mathbf{- 1 3 . 8 4}$ & 8.80 & -22.53 & 8.80 \\
\hline ARM_RAOB & -15.51 & 6.91 & $\mathbf{- 1 2 . 9 5}$ & 7.07 & -21.1 & 7.07 \\
\hline MIR 183+/-1 & & & & & & \\
\hline NWS_RAOB & $\mathbf{- 1 9 . 9 4}$ & 11.42 & -21.87 & 11.53 & -23.65 & 11.53 \\
\hline ARM_RAOB & $\mathbf{- 1 1 . 2 0}$ & 4.29 & $\mathbf{- 1 4 . 3 0}$ & 4.67 & -15.64 & 4.67 \\
\hline
\end{tabular}




\section{REFERENCES}

Ackerman, T. P. and G. M. Stokes, 2003: The Atmospheric Radiation Measurement Program. Physics Today, 55(1), 38-44.

Cimini, D., E. R. Westwater, Y. Han, and S. J. Keihm, 2003: Accuracy of Ground-based Microwave Radiometer and Balloon-borne Measurements during the WVIOP2000 Field Experiment. IEEE Trans. Geosci. Remote Sens., (in press).

Clough, S. A., M. J. Iacono, and J. L. Moncet, 1992: Line-by-line calculation of atmospheric fluxes and cooling rates: Application to water vapor. J. Geophys. Res., 97, 15761-15785.

, P. D. Brown, J. C. Liljegren, T. R. Shippert, D. D. Turner, R. O. Knuteson, H. E. Revercomb, and W. L. Smith, 1996: Implications for Atmospheric State Specification from the AERI/LBLRTM Quality Measurement Experiment and the MWR/LBLRTM Quality Measurement Experiment. Proc. Sixth Atmospheric Radiation Measurement (ARM) Science Team Meeting, March 3-7, 1996, San Antonio, Texas. [Available at http://www.arm.gov/docs/documents/technical/conf_9603/index.html.]

, P. D. Brown, D.D. Turner, T.R. Shippert, J.C. Liljegren, D.C. Tobin, H.E. Revercomb, and R.O. Knuteson, 1999: Effect on the Calculated Spectral Surface Radiances Due to MWR Scaling of Sonde Water Vapor Profiles. Proc. Ninth Atmospheric Radiation Measurement (ARM) Science Team Meeting, San Antonio, Texas. [Available at http://www.arm.gov/docs/documents/technical/conf 9903/index.html.]

Curry, J. A., W. B. Rossow, D. Randall, and J. L. Schramm, 1996: Overview of Arctic cloud and radiation characteristics. Bull. Amer. Meteor. Soc., 9, 1721-1764.

, P. V. Hobbs, M. D. King, D. A. Randall, P. Minnis, G. A. Isaac, J. O. Pinto, T. Uttal, A. Bucholtz, D. G. Cripe, H. Gerber, C. W. Fairall, T. J. Garrett, J. Hudson, J. M. Intrieri, C. Jakob, T. Jensen, P. Lawson, D. Marcotte, L. Nguyen, P. Pilewskie, A. Rangno, D. C. Rogers, K. B. Strawbridge, F. P. J. Valero, A. G. Williams, and D.Wylie, 2000: FIRE Arctic Clouds Experiment. Bull. Amer. Meteor. Soc., 81, 5-28.

Falcone, V. J., M.K. Griffin, R.G. Isaacs, J.D. Picle, J.F. Morrisey, A.J. Jackson, A. Bussey, R. Kakar, J. Wang, P. Racette, D. J. Boucher, B. J. Thomas, and A. M. Kishi, 1992: "DMSP F11 SSM/T-2 calibration and validation," Environ. Res. Paper 1111, PL-TR-92-2293 [Available from Philips Laboratory, Hanscom Air Force Base, MA 01731-5000.]

Han, Y., and E. R. Westwater 2000: Analysis and improvement of tipping calibration for ground-based microwave radiometers. IEEE Trans. Geosci. Remote Sens., 38, 1260-1277.

Hogg, D.C., F.O. Guiraud, J.B. Snider, M.T. Decker and E.R. Westwater, 1983: A steerable dual-channel microwave radiometer for measurement of water vapor and liquid in the troposphere. J. Climate. Appl. Meteor., 22, 789-806.

Jackson, D.M. and A.J. Gasiewski, 1995: Millimeter-wave radiometric observations of the troposphere: A comparison of measurements and calculations based on radiosonde and Raman lidar. IEEE Trans. Geosci. Remote Sens., 33, 3 - 14.

Janssen, M. A., 1985: A new instrument for the determination of radio path delay due to atmospheric water vapor. IEEE Trans. Geosci. Remote Sens., GE-23(4), 485-490.

Jones, D. C. and P. Racette, 1998, Ground-based retrieval of very low to high columnar integrated water vapor using combined millimeter-wave and microwave observations. Int. Geosci. Remote Sens. Symp

Kakar, R. K. and B. H. Lambrigtsen, 1998: Retrieval of clear sky moisture profiles using $183 \mathrm{GHz}$ water vapor line. J. Climate Appl. Meteor., 23, 1110-1114. 
Kiedron, P.,J. Michalsky, B. Schmid, D. Slater, J. Berndt, L. Harrison, P. Racette, E. Westwater, and Y. Han, 2001: A robust retrieval of water vapor column in dry Arctic conditions using the Rotating Shadowband Spectroradiometer. J. Geophys. Res., 106 (D20), 24007-24016.

Lesht, B. M., 1999: Reanalysis of radiosonde data from the 1996 and 1997 water vapor intensive observation periods: Application of the Väisälä RS-80H contamination correction algorithm to dual-sonde soundings. Proc. Ninth Annual Atmospheric Radiation Measurement (ARM) Science Team Meeting, N. Burleigh and D. Carrothers, Eds, (http: $\mid$ www.db.arm.gov|Publist).

Leuski, V. and E. R. Westwater, 2001: Measurement of boundary-layer temperature profiles by a scanning 5-mm radiometer during the 1999 Arctic Winter Experiment and WVIOP'2000, Proc. $11^{\text {th }}$ Atmospheric Radiation Measurement (ARM) Science Team Meeting, Atlanta, Georgia., (http://www.arm.gov/docs/documents/technical/conf_0103/author.html\#L).

Liebe, H. J., and D. H. Layton, 1987: Millimeter wave properties of the atmosphere: laboratory studies and propagation modeling. National Telecommunications and Information Administration (NTIA) Report 87-24, $74 \mathrm{pp}$.

1989: MPM, an atmospheric millimeter wave propagation model. Int. J. Infrared and Millimeter Waves, 10, 631-650.

, G. A. Hufford, and M. G. Cotton, 1993: Propagation modeling of moist air and suspended water/ice particles at frequencies below 1000. AGARD Conf. Proc. 542, Atmospheric propagation effects through natural and man-made obscurants for visible through MM-wave radiation, pp. 3.1 - 3.10. [Available from NASA Center for Aerospace Information, Linthicum Heights, MD.]

Liljegren,, J. C., 2000: Automatic self-calibration of ARM microwave radiometers. Microwave Radiometry and Remote Sensing of the Earth's Surface and Atmosphere, P. Pampaloni and S. Paloscia, Eds. VSP Press, 433-441.

Prigent, C., A. Sand, C. Klapisz, Y. Lemaitre, 1994: Physical retrieval of liquid water contents in a North Atlantic cyclone using SSM/I data. Quart. J. Roy. Meteor. Soc., 120, 1179-1207.

Racette, P., J. R. Wang, P. Evans, R. Saunders, A. Gasiewski, and D. Jackson, 1995: A calibration experiment using millimeter-wave imaging radiometer at the UK Meteorological Office calibration facility. Proc. Int. Geosc. Remote Sens. Symp (IGARSS'95), 809 - 811.

R.F. Adler, J.R. Wang, A.J. Gasiewski, D.M. Jackson and D.S. Zacharias, 1996: A millimeter-wave imaging radiometer for cloud, precipitation and atmospheric water vapor studies. J. Atmos. Ocean. Tech, 13, 610-619.

M. Triesky, and D.C. Jones, 1998: A multichannel microwave radiometer uses reference averaging for calibration: precision approaches that of a total power radiometer. Proc. Int. Geosc. Remote Sens. Symp. (IGARSS'98).

Revercomb, H. E., H. Buijs, H. B. Howell, D. D. LaPorte, W. L. Smith, and L. A. Sromovsky, 1998: Radiometric calibration of IR Fourier Transform Spectrometers: solution to a problem with the High-Resolution Interferometer Sounder. Appl. Opt., 27, 3210-3218.

Rodgers, C. D., 1976: Retrieval of atmospheric temperature and composition from remote measurements of thermal radiation. Rev. Geophys. Space Phys., 44, 609-624.

Rosenkranz, P. W. 1998: Water vapor microwave continuum absorption: a comparison of measurements and models. Radio Sci., 33, 919-928.

Serreze, M. C., R.G. Barry, and J.E. Walsh, 1995a: Atmospheric Water Vapor Characteristics at $70^{\circ}$ N. $J$. Cli., 8, 719-731. 
, M.C. Rehder, R.G. Barry, J.D. Kahl, and N.A. Zaitseva, 1995b: The distribution and transport of atmospheric water vapour over the Arctic basin. Int. J. Climatol., 15, $709-727$.

Siegenthaler, A., O. Lezeaux, D.G. Feist, and N. Kampfer, 2001: First water vapor measurements at 183 GHz from the high alpine station Jungfraujoch. IEEE Trans. Geosci. Remote Sens., 39, pp. 2084 2086.

Stokes, G. M. and S. E. Schwartz, 1994: The Atmospheric Radiation Measurement (ARM) Program: Programmatic background and design of the cloud and radiation tested. Bull. Amer. Meteor. Soc., 75, 1201-1221.

Stamnes, K., R.G. Ellingson, J.A. Curry, J.E. Walsh, and B.D. Zak, 1999: Review of science issues, deployment strategy, and status for the ARM North Slope of Alaska-Adjacent Arctic Ocean climate research site. J. Climate, 12, $46-63$.

Tikhonov, A. N., and V. Y. Arsenin, 1977: Solutions of Ill-Posed Problems. V.H. Winston and Sons, 258 pp.

Twomey, S., 1977: Introduction to the mathematics of inversion in remote sensing and indirect measurements. Elsevier, 243 pp.

Tobin, D., C., F.A. Best, P.D. Brown, S.A. Clough, R.G. Dedecker, R.G. Ellingson, R.K. Garcia, H.B. Howell, R.O. Knuteson, E.J. Mlawer, H.E. Revercomb, J.F. Short, P.F.W van Delst, and V.P. Walden, 1999: Downwelling spectral radiance observation at the SHEBA ice station: Water vapor continuum measurements from 17 to 26um,"J. Geophys. Res., 104, 2081 - 2092.

Turner, D. D. , B. Lesht, S. A. Clough, J. C. Liljegren, H. E. Revercomb, and D. C. Tobin, 2003: Dry bias and variability in Văisălä RS80-H radiosondes: The ARM experience. J. Atmos. Ocean. Technol. (in press).

Wade, C. G., 1994: An evaluation of problems affecting the measurement of low relative humidity on the U.S. radiosonde. J. Atmos. Ocean. Technol., 11, 687-700.

Wang, J., H. L. Cole, D. J. Carlson, E. R. Miller, K. Beierle, A. Paukkunen, and T. K. Laine, 2002: Corrections of humidity measurement errors from the Vaisala RS80 radiosonde - Application to TOGA-COARE data. J. Atmos. Ocean. Technol., 19(7), 981-1002.

, J.L. King, T.T. Wilheit, G. Szejwach, L.H. Gesell, R.A. Nieman, D.S. Niver, B.M. Krupp, and J.A. Gagliano, 1983: Profiling atmospheric water vapor by microwave radiometry J.Climate Appl. Meteor., 22, 779-788.

, and L. A. Chang, 1990: Retrieval of water vapor profiles from microwave radiometric measurements near 90 and $183 \mathrm{GHz}$. J. Appl. Meteor., 29, $1006-1013$.

, W. C. Boncyk, L. R. Dod, and A. K. Sharma, 1992:Retrieval of total precipitable water over high-latitude regions using radiometric measurements near 90 and $183 \mathrm{GHz}$. J. Appl. Meteor., 31(12), 1368-1378.

P. Racette, and L. A. Chang, 1997: MIR Measurements of Atmospheric Water Vapor Profiles. IEEE Trans. Geosci Remote Sens., 35, 212 - 223.

,P. Racette, J. D. Spinhirne, K.F. Evans, W.D.Hart, 1998: Observations of cirrus clouds with airborne MIR, CLS, and MAS during SUCCESS. Geophys. Res. Lett., 25(8), 1145 - 1148.

, G. Liu, J. D. Spinhirne, P. Racette, and W. Hart, 2001a: Measurements of cirrus clouds with airborne MIR, CLS, and MAS during FIRE III-ACE. J. Geophys. Res., 106(D4), 15,251-15,263. 
, P. Racette, and M. E. Triesky, 2001b: Retrieval of integrated water vapor by the millimeterwave radiometric measurements in the arctic region during FIRE-ACE. IEEE Trans. Geosci. Remote Sens., 39(3), 595-605.

P. Racette, and M. E. Triesky, and W. Manning, 2002: Retrievals of column water vapor using millimeter-wave radiometric measurements. IEEE Trans. Geosci. Remote Sens., 40(6), 1220-1229.

Westwater, E.R., 1978: The accuracy of water vapor and cloud liquid determinations by dual-frequency ground-based microwave radiometry," Radio Sci, 13(4), 677-685.

1993: Ground-based microwave remote sensing of meteorological variables. Atmospheric Remote Sensing by Microwave Radiometry, M. Janssen, Ed., John Wiley \& Sons, Inc., 145-213.

, J.B. Snider, and M.J. Falls, 1990: Ground-based radiometric observations of atmospheric emission and attenuation at $20.6,31.65$, and $90.0 \mathrm{GHz}$ : A comparison of measurements and theory. IEEE Trans. Antennas Propagat., 38(10), 15690-15800.

, Y. Han, V. G. Irisov, V. Leuskiy, E. N. Kadygrov, and S. A. Viazankin, 1999: Remote sensing of boundary-layer temperature profiles by a scanning 5-mm microwave radiometer and RASS: Comparison experiment. J. Atmos. Ocean. Technol., 16(7), 805-818.

B. B. Stankov, D. Cimini, Y. Han, J. A. Shaw, B. M. Lesht, and C. N. Long, 2003: Radiosonde humidity soundings and microwave radiometers during Nauru99, J. Atmos. Ocean. Technol., 20(7), 953-971. 
Figure 1

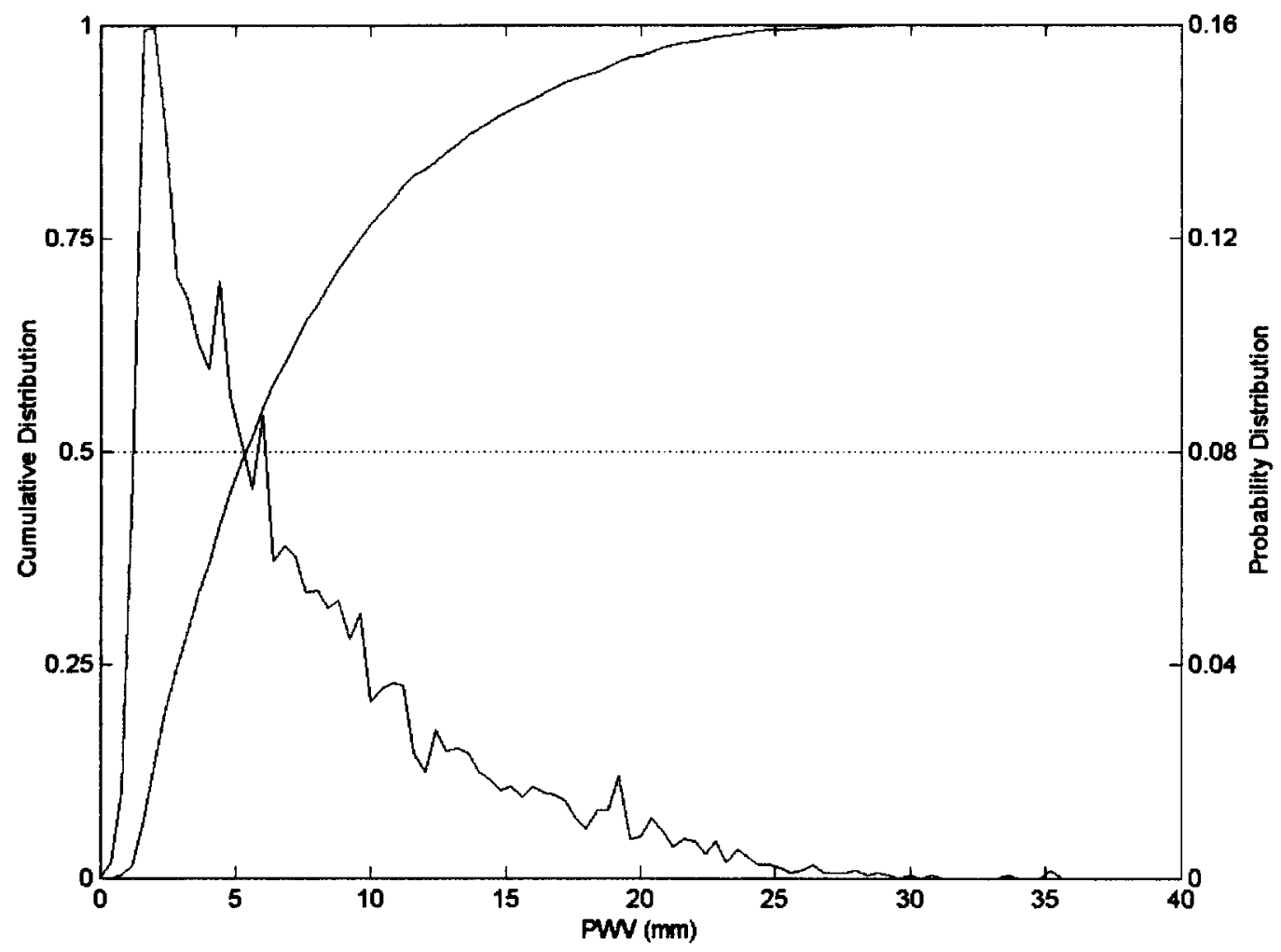

Figure 1: Probability and cumulative distribution functions for PWV derived from RAOBs at Barrow, AK (1990 - 1996). 
Figure 2
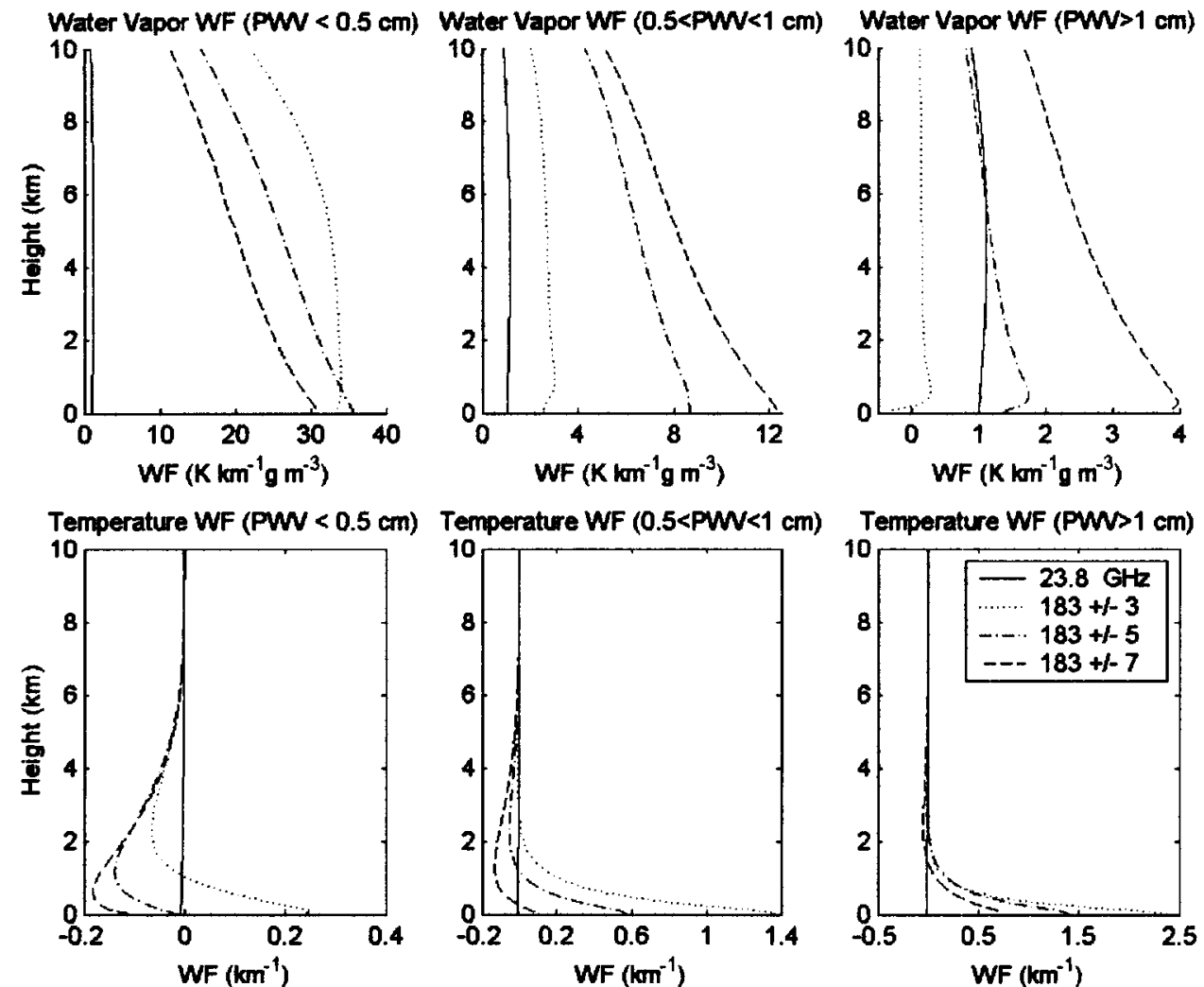

Figure 2: Average vapor density and temperature weighting functions for three ranges of PWV. The absorption model used is Rosenkranz (1998). 
Figure 3

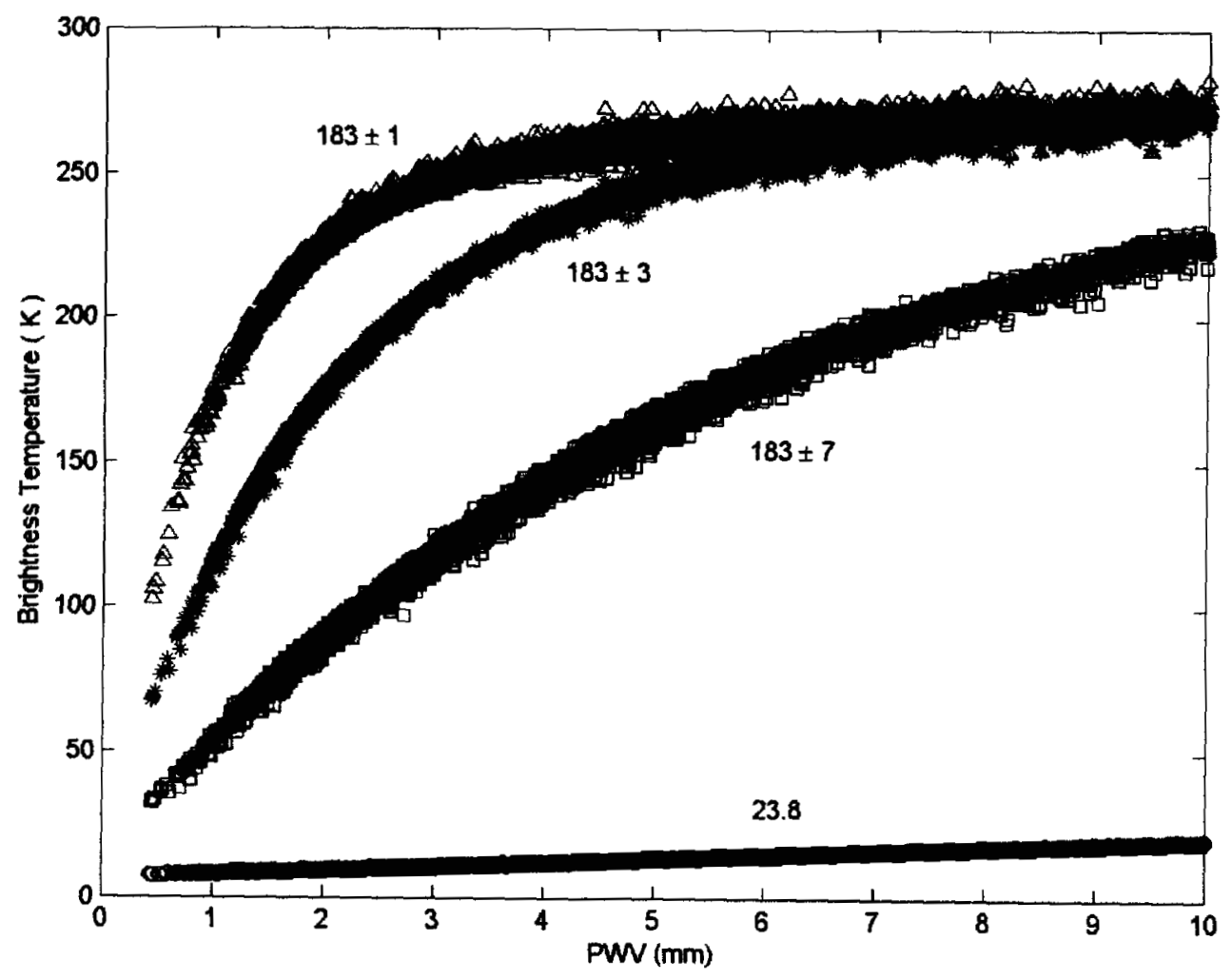

Figure 3: Brightness temperature versus precipitable water vapor at several frequencies. Calculations were based upon the 7-year collection of RAOBs at Barrow, Alaska. The absorption model used is from Rosenkranz (1998). 
Figure 4

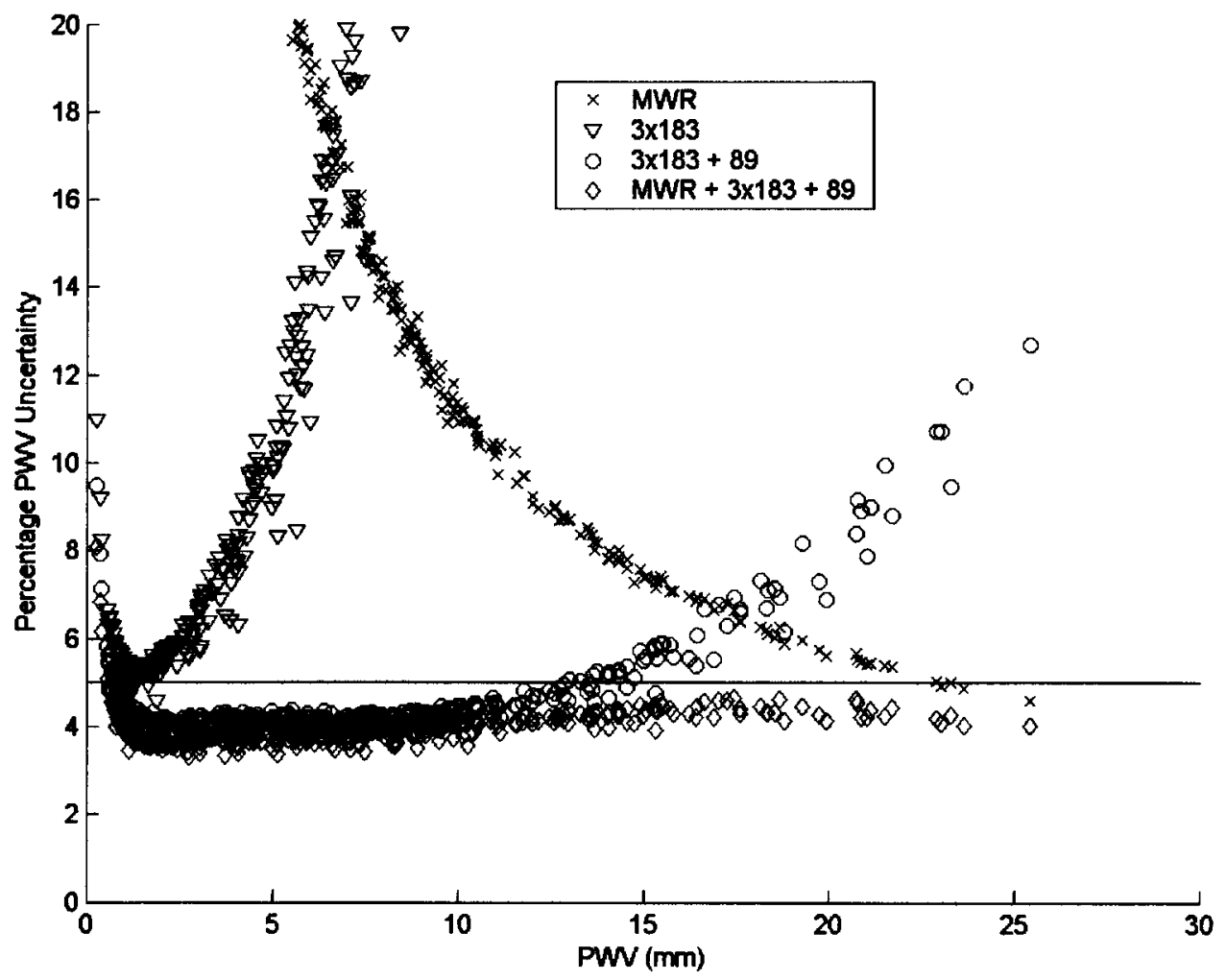

Figure 4: The percentage uncertainty in retrieved PWV versus true PWV for a selection of clear high-latitude model atmospheres using the four different channel combinations. See text for a definition of the frequency combinations. 
Figure 5

(a)

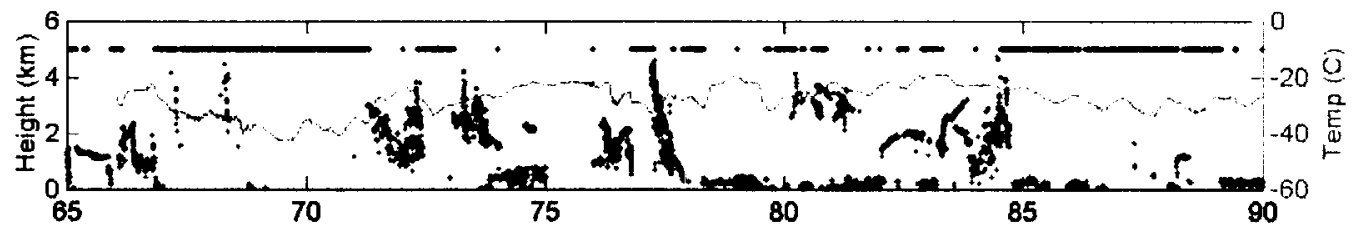

(b)

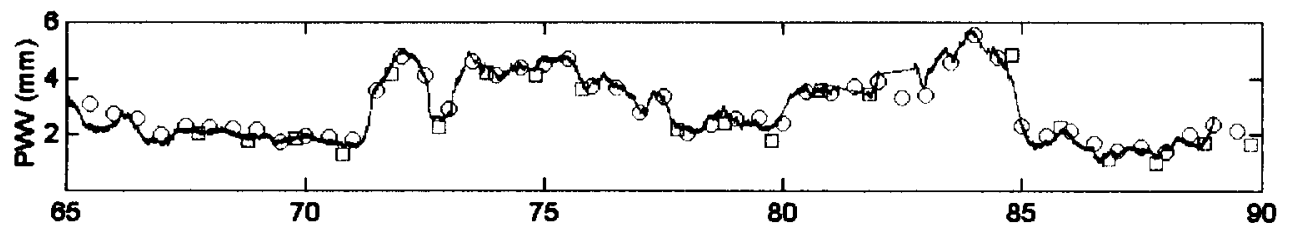

(c)

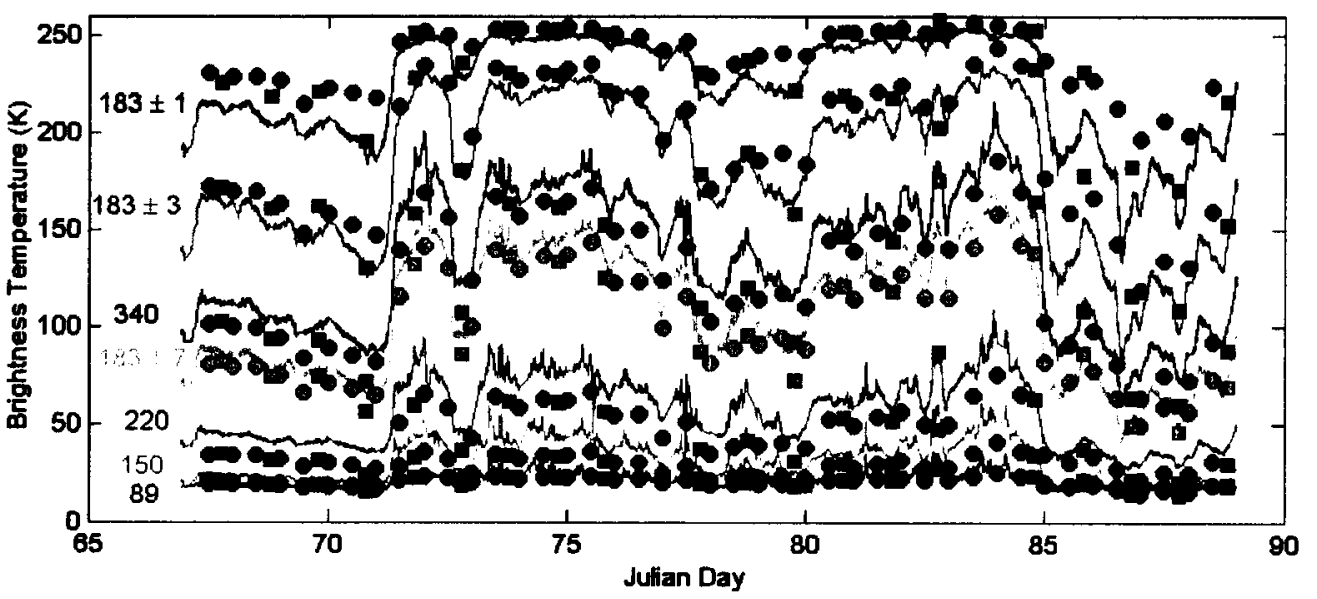

Figure 5: Observations made during the NSA experiment. (a) Ceilometer data indicating cloud-base height (light blue points), periods of clear-sky conditions are indicated by the blue points at $5000 \mathrm{~m}$, and near-surface temperature (green line). (b) PWV (line) as measured using MWR after calibration algorithm modification. PWVs are calculated from the NWS (circles) and ARM (squares) radiosondes. (c) Brightness temperatures measured by the MIR and MWR and forward-modeled TBs based on radiosonde measurements and the model published in Rosenkranz (1998). 
Figure 6

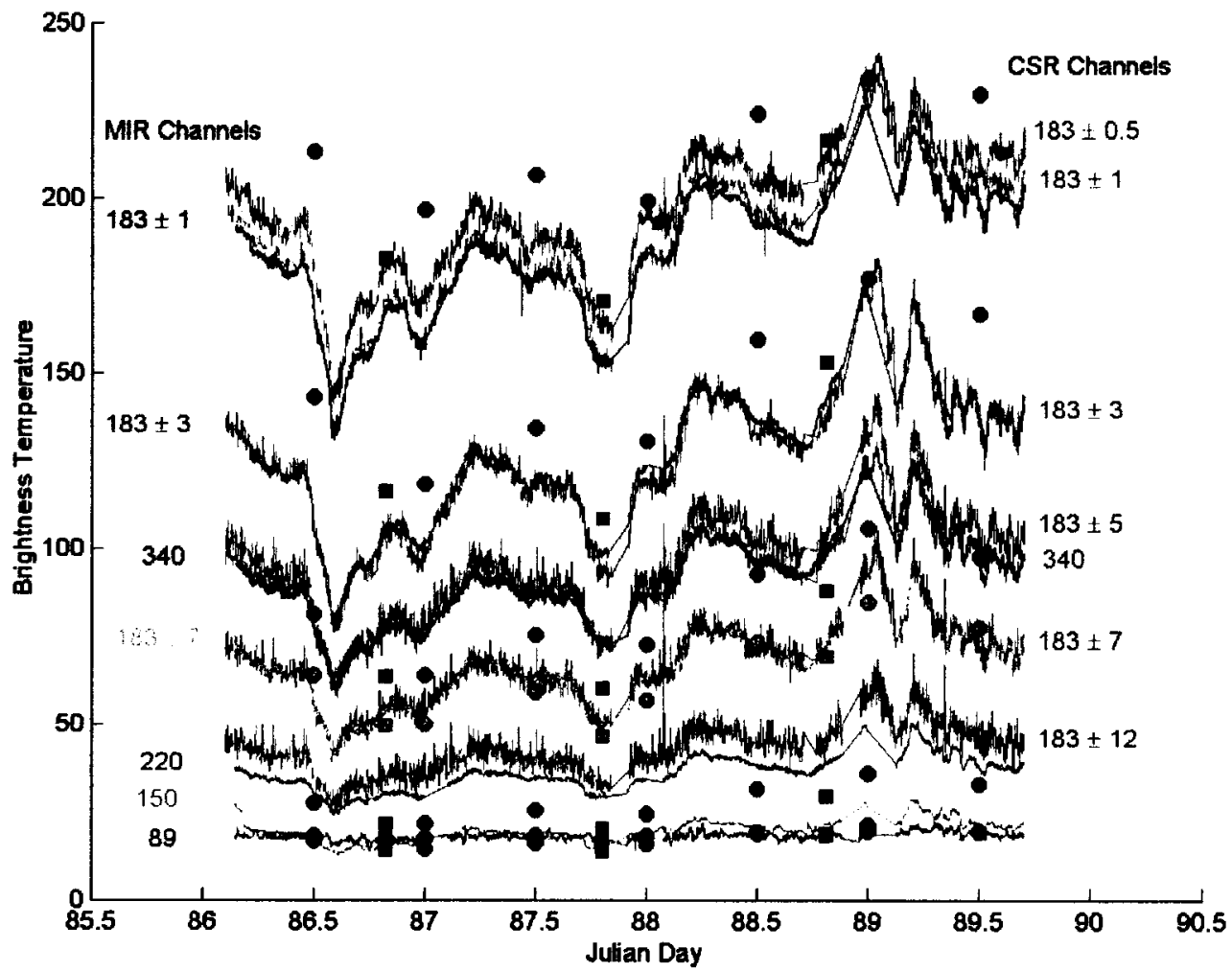

Figure 6: Comparisons of MIR and CSR TB measurements. 


\section{Figure 7}

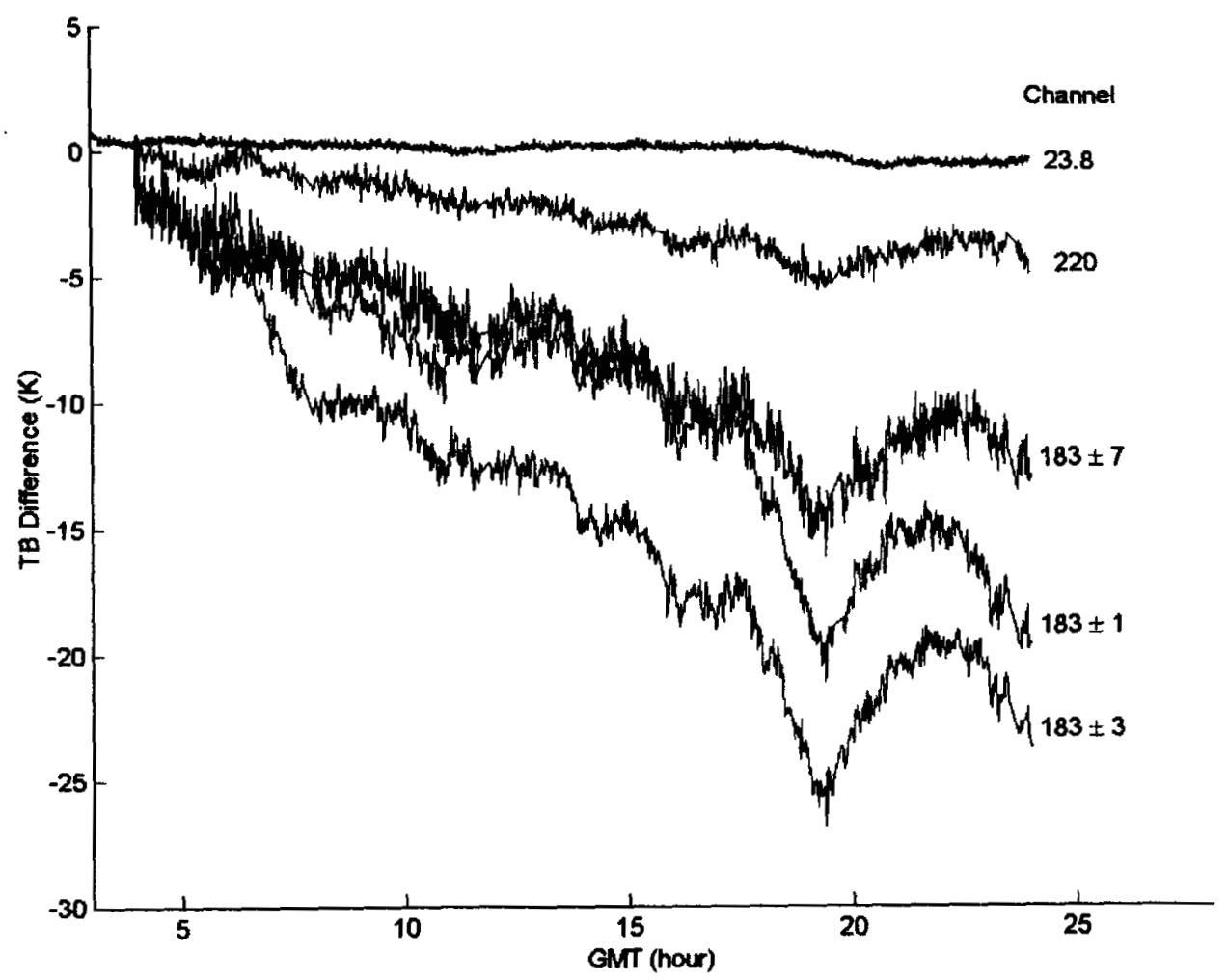

Figure 7: Brightness temperature differences measured by the MIR and the MWR on Julian day 70 . 
Figure 8a

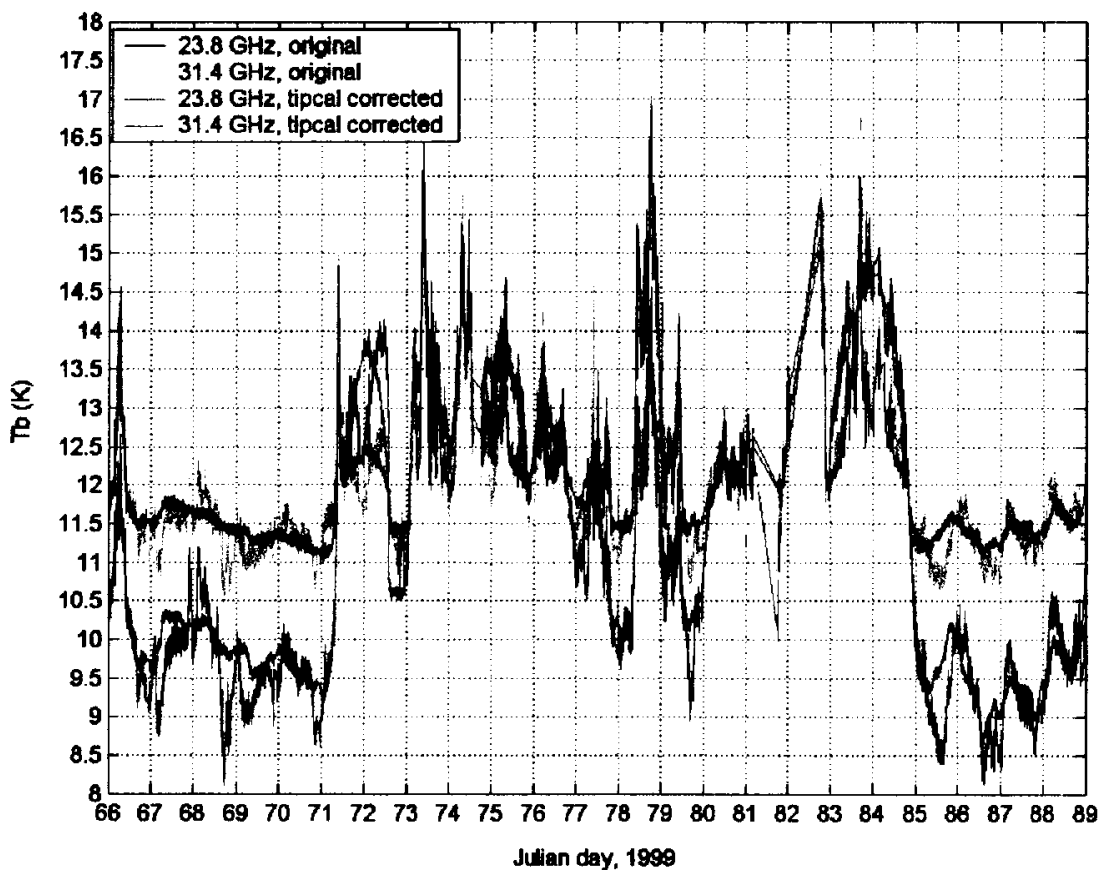

Figure 8b

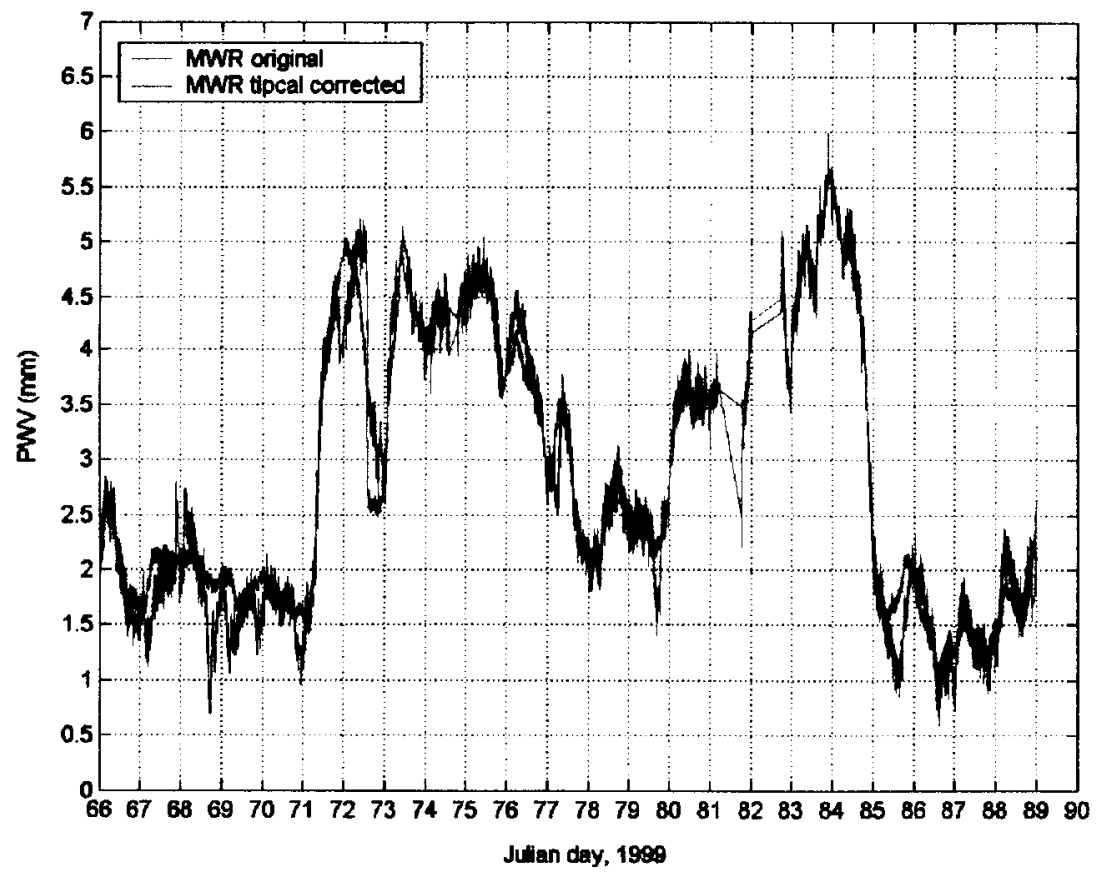

Figure 8: (a) MWR TBs using original calibration algorithm and modified calibration algorithm. (b) PWVs derived from original and modified calibration measurements. 
Figure 9

(a)

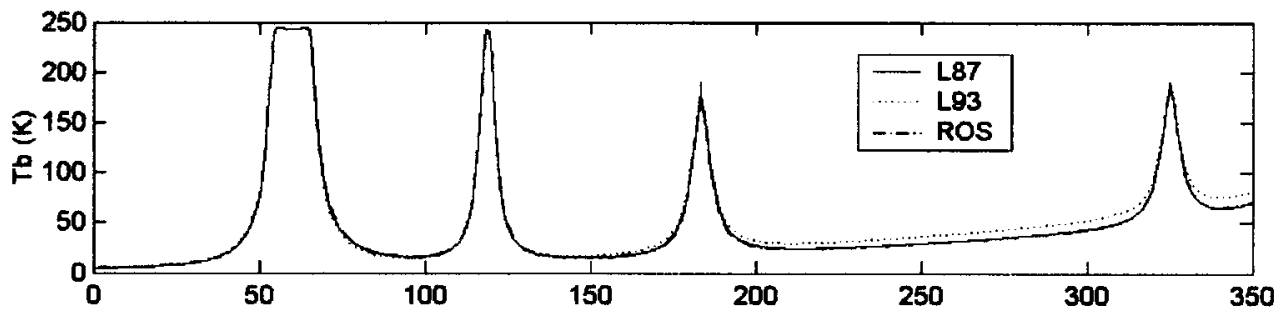

(b)

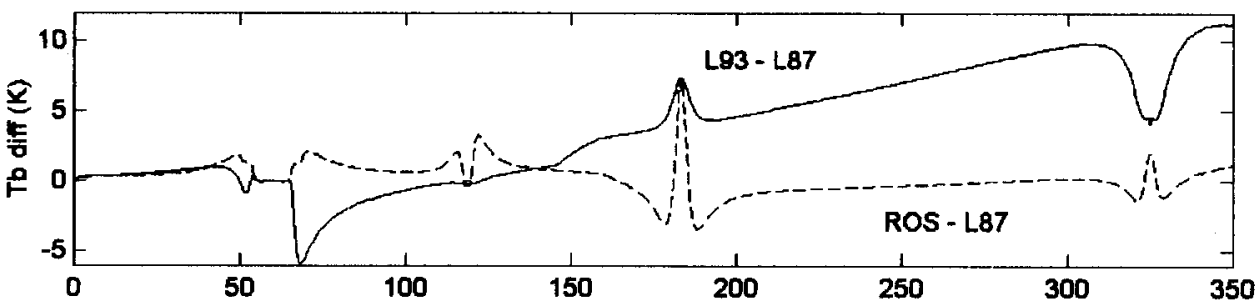

(c)

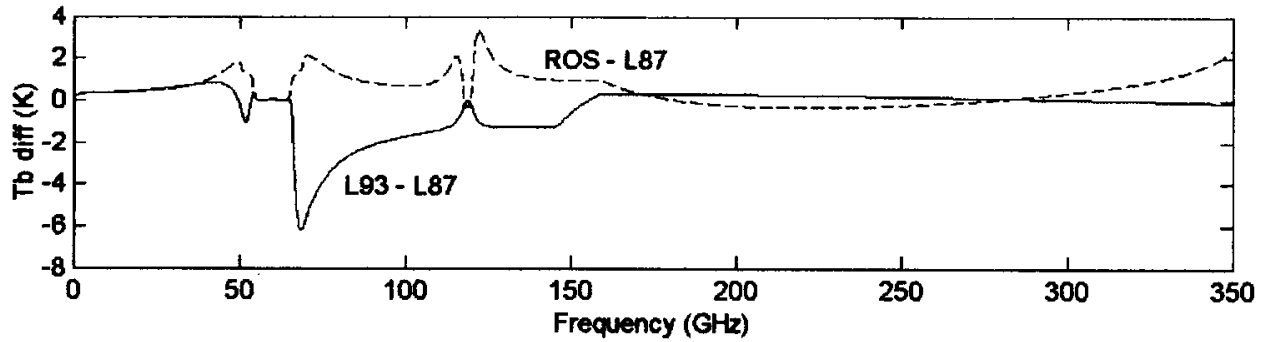

Figure 9: (a) Forward-modeled brightness temperatures using three different absorption models. (b) Differences in TBs of the L93 and ROS model with respect to L87. (c) Differences in the models for a dry $(\mathrm{PWV}=0)$ atmosphere. 
Figure 10

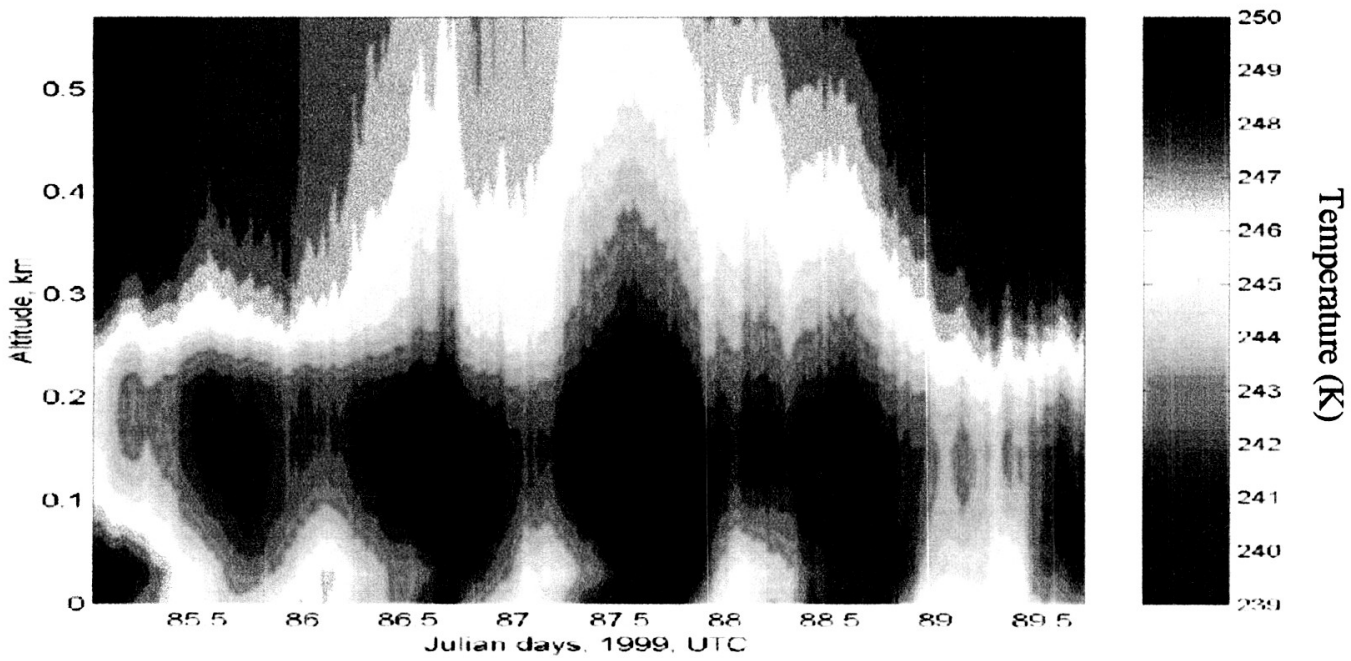

Figure 10: Temperature time-height cross sections retrieved using the ETL $60 \mathrm{GHz} \mathrm{O} 2$ Scanning Radiometer with a first guess derived from RAOBS. 
Figure 11

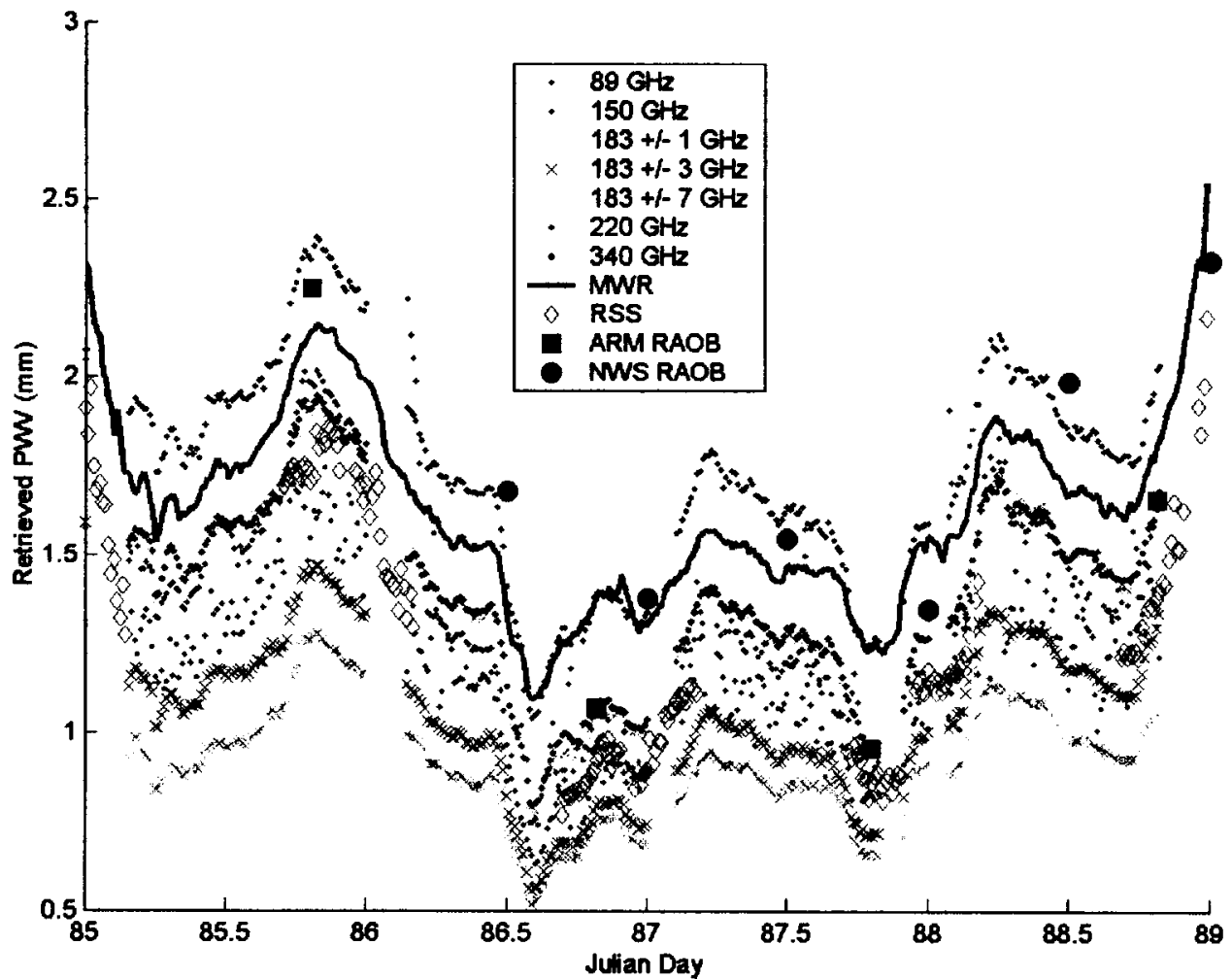

Figure 11: Clear-sky single-channel PWV retrievals using a variety of MMW channels. 